\title{
EEG signatures of arm isometric exertions in preparation, planning and execution
}

\author{
Bahman Nasseroleslami* ${ }^{1}$, Heba Lakany and Bernard A. Conway \\ Department of Biomedical Engineering, University of Strathclyde, \\ 106 Rottenrow, Glasgow G4 0NW, Scotland, UK. \\ E-Mails: bahman.nasseroleslami@strath.ac.uk, heba.lakany@strath.ac.uk,b.a.conway@strath.ac.uk
}

22 Pages, 7 Figures, 4 Tables, 2 Equations, 11 Suppl. Figures and 2 Suppl. Tables,

Abstract: 327 words, Manuscript: 10302 words.

\begin{abstract}
The electroencephalographic (EEG) activity patterns in humans during motor behaviour provide insight into normal motor control processes and for diagnostic and rehabilitation applications. While the patterns preceding brisk voluntary movements, and especially movement execution, are well described, there are few EEG studies that address the cortical activation patterns seen in isometric exertions and their planning. In this paper, we report on time and time-frequency EEG signatures in experiments in normal subjects $(n=8)$, using multichannel EEG during motor preparation, planning and execution of directional centre-out arm isometric exertions performed at the wrist in the horizontal plane, in response to instruction-delay visual cues. Our observations suggest that isometric force exertions are accompanied by transient and sustained event-related potentials (ERP) and event-related (de-)synchronisations (ERD/ERS), comparable to those of a movement task. Furthermore, the ERPs and ERD/ERS are also observed during preparation and planning of the isometric task. Comparison of ear-lobe-referenced and surface Laplacian ERPs indicate the contribution of superficial sources in supplementary and pre-motor $\left(\mathrm{FC}_{\mathrm{z}}\right)$, parietal $\left(\mathrm{CP}_{\mathrm{z}}\right)$ and primary motor cortical areas $\left(\mathrm{C}_{1}\right.$ and $\left.\mathrm{FC}_{1}\right)$ to ERPs (primarily negative peaks in frontal and positive peaks in parietal areas), but contribution of deep sources to sustained time-domain potentials (negativity in planning and positivity in execution). Transient and sustained ERD patterns in $\mu$ and $\beta$ frequency bands of ear-lobe-referenced and surface Laplacian EEG indicate the contribution of both superficial and deep sources to ERD/ERS. As no physical displacement happens during the task, we can infer that the underlying mechanisms of motor-related ERPs and ERD/ERS patterns do not only depend on change in limb coordinate or muscle-length-dependent ascending sensory information and are primary generated by motor preparation, direction-dependent planning and execution of isometric motor tasks. The results contribute to our understanding of the functions of different brain regions during voluntary motor tasks and their activity signatures in EEG can shed light on the relationships between large-scale recordings such as EEG and other recordings such as single unit activity and fMRI in this context.
\end{abstract}

Keywords: Event-Related (De-)Synchronisation (ERD/ERS), Event-Related Potentials (ERP), Isometric Force, Planning, Execution, EEG.

Submitted to NeuroImage on 16 July 2013.

Revision 1 submitted on 4 October 2013.

Revision 2 submitted on 29 October 2013.

Revision 3 submitted on 25 November 2013.

\footnotetext{
${ }^{1}$ *Corresponding Author. Present Address: Department of Biology, Northeastern University, 134 Mugar Life Sciences, 360 Huntington Avenue, Boston, MA 02115, USA. Tel: +1 617373 7070, Fax: +1 617373 3724, E-Mail: b.nasseroleslami@neu.edu
} 


\section{Introduction}

Motor-related brain activity is of interest not only from physiological and neuroanatomical perspective, but equally in a rehabilitation engineering context. How different regions of brain are activated during various motor tasks can give invaluable insight into the integration mechanisms in neural control and planning of movement and this knowledge can be instrumental in the development and testing of novel forms of assistive devices and rehabilitation programmes (Birbaumer et al., 2008; McFarland et al., 2006; Wolpaw, 2007). Among the brain recording techniques used for clinical or scientific purposes (Hatsopoulos and Donoghue, 2009), invasive recordings provide good spatial resolution. However, in human studies, non-invasive recordings such as electroencephalography (EEG) are often the most practical approach to gain access to the summed spatial, spectral and temporal characteristics of neuronal activity associated with motor behaviour (Waldert et al., 2009) where knowledge on the dynamics of synchronized activity in network formation and interactions can be sought. Such information can also be of interest for clinical diagnostics and therapeutic interventions (Reis et al., 2008).

From the early discovery of Bereitschaftspotential and contingent negative variation (CNV) (see Shibasaki and Hallett, 2006, for a review), various studies have investigated motor-related potentials (MRP) (Babiloni et al., 1999; Jahanshahi et al., 1995; Neuper et al., 2006 ), the $\mu$-rhythm (da Silva 2006), event-related synchronisation (ERS) in $\delta$ and $\theta$ bands and event-related de-synchronisation (ERD) in $\alpha(\mu)$ and $\beta$ frequency bands (see Graimann and Pfurtscheller, 2006; Waldert et al 2009). However, there are few EEG studies that use sequenced execution protocols such as instruction-delay to reveal the involved brain regions in planning and execution stages of tasks, as practiced in primate single cell movement ( Cisek and Kalaska, 2004, 2005; Sergio et al., 2005) and isometric task (Sergio and Kalaska, 2003; Sergio et al., 2005) recording studies. Reach-target classification in instruction-delay reaching tasks (Hammon et al., 2008), or MRPs in planning of impeded elbow flexion/extension task (MacKay and Bonnet, 1990) are the only examples for movement and the only EEG study on isometric finger tasks with planning pre-cues before action (Ulrich et al., 1998) discusses the MRP patterns only. Other EEG studies on isometric tasks discuss different phenomena (see Discussions, Section 4.1). Consequently there is no systematic data about ERD/ERS patterns in planning and execution of isometric tasks. Following our previous report (Nasseroleslami et al., 2011) we try to address this gap in this paper. We are interested to explore the existence of consistent signal features associated with preparation, planning and execution of isometric tasks, and their similarity to those of movement tasks and movement imagery (Caldara $e t$ al., 2004; Neuper et al., 2006).

In this study, we have asked subjects to prepare, plan for, and exert isometric force in a centre-out arm task, according to a visual cue target point, while EEG is recorded. The spatial distribution of signal features across scalp can imply the involved brain regions and their laterality, when an isometric motor task is attempted.

\section{Materials and Methods}

\subsection{Setup and Recording}

2.1.1. EEG. EEG is recorded by Synamps $2{ }^{\circledR}$ System (Compumedics Neuroscan, Charlotte, NC, USA), using an electrode cap with $\mathrm{Ag} / \mathrm{AgCl}$ sintered ring electrode set (EASYCAP GmbH, Herrsching-Breitbrunn, Germany), referenced to earlobes and with a forehead location $\left(\mathrm{AF}_{\mathrm{z}}\right)$ used as ground. EEG is band-pass filtered between $0.05-500 \mathrm{~Hz}$ and digitally sampled at $2000 \mathrm{~Hz}$ and captured using SCAN $^{\circledR}$ software (Compumedics Neuroscan, 
Page 3 of 33

Charlotte, NC, USA). A total of 73 EEG channels were recorded from the scalp in full 10\% arrangement (Guidelines for Standard Electrode Position Nomenclature, American Clinical Neurophysiology Society, 2006). Contact impedances of all recorded electrodes were below to $5 \mathrm{k} \Omega$ before recording.

2.1.2. Force. Force is recorded by a Nano $25^{\circledR} 6$-axial Torque and Force transducer and power supply/interface box (ATI Industrial Automation, Apex, NC, USA) and is recorded by Power $1401^{\circledR} \mathrm{mk} 1.5$ (Cambridge Electronic Design Limited, Cambridge, England, UK), sampled at $2000 \mathrm{~Hz}$ and recorded by Spike ${ }^{\circledR}$ Software (Cambridge Electronic Design Limited, Cambridge, England, UK). A spherical knob ( $\varphi=53 \mathrm{~mm})$ is attached on top of the sensor and the sensor is rigidly fixed to the right side of the seat within easy reach of the subject's hand (See Figure 1b).

2.1.3. Visual Cues. Subjects are seated approximately $1.75 \mathrm{~m}$ away from the CRT display (75Hz) to minimize the effect of eye movement and movement artefacts. Visual cues and dynamic visual feedback of force are generated and presented to the subjects by the Psychophysics Toolbox (Brainard, 1997; Pelli, 1997), via MATLAB $^{\circledR}$ (The Mathworks, Inc., Natick, MA, USA).

2.1.4. Synchronisation. The synchronization among the appearance of visual cues, the EEG recording system, and the force recording system is achieved by an event cable connected to digital inputs of the systems. The time delays between the generated event for each visual cue and the recording events are limited to $1 \mathrm{~ms}$. The visually presented feedback of force has a delay of $15-65 \mathrm{~ms}$ and the mode of $45 \mathrm{~ms}$. This delay is the delay between acquisition and visualisation of force and not between presented cues, recorded EEG and recorded force.

\subsection{Subjects}

All subjects provided signed informed consent. Protocols for work on normal subjects were approved by the University of Strathclyde ethics committee. The study conforms with The Code of Ethics of the World Medical Association (Declaration of Helsinki). A total of 8 (5 male) healthy subjects without history of neuromuscular disease volunteered for the experiment. Subjects had normal or corrected to normal vision.

\subsection{Experiment}

Subjects sat in a modified motorsport car seat (which provides a high degree of trunk stability), in front of a monitor and in easy reach of the knob of the force measuring device, as described above. Subjects were instructed to exert centre-out force exertions to left, right, forward and backward, within the horizontal plane (See Figure 1a). This means exertion of force toward a specific direction, without displacement. This is different from sustained isometric contraction in which the output force and moment are zero. An arm rest was used to support the forearm above the wrist (See Figure 1b). The target force was set to $30 \%$ of maximum voluntary contraction for each subject. Subjects were given time to practice and learn the task before the experiment proper. To minimize EEG contamination by EMG artefacts, subjects were repeatedly being asked verbally during the experiment to relax and not to contract their shoulder or neck muscles. This, together with using proper seat and arm-rest minimized the artefacts.

The sequence of visual cues is presented to the subject in an instruction-delay paradigm (vs. reactiontime paradigm) as depicted and explained in Figure 2. Subjects rest first. After this, the screen turns white (Rest Cue: RC) and the subject remains at rest. Next, the Attention Cue (AC) appears as a black circle in the middle of 
Page 4 of 33

the screen and this is a cue for preparation. Afterwards, a Directional Cue (DC) appears as another black circle in one of the 4 random directions and instructs the subject to plan in the specified direction (Subject takes no physical action). Finally, the middle black circle changes to red, which is the GO signal (GO) and instructs the subject to start the isometric exertion toward the indicated direction. Simultaneously, the subject observes on the screen the direction and magnitude of the exerted force as a dynamically changing line anchored at the centre point. After this a new trial starts.

$\mathrm{RC}, \mathrm{AC}$, and DC stages last a random duration between 2 and 3 seconds, GO lasts between 3 and 5 seconds and the rest period lasts between 5 and 7 seconds, for each trial. Trials are conducted in sets of 7-8 minute recordings with time in between for rest. Each subject attempts a minimum of 220 trials (i.e. about 55 trials in each direction).

\subsection{Data Analysis}

Data analysis was performed using scripts written in MATLAB ${ }^{\circledR}$ (Mathworks, Inc., Natick, MA, USA). The acquired signals were visually inspected for eye movement, jaw clenching, blink, EMG, ECG, movement, and electrode artefacts using a custom MATLAB GUI and contaminated EEG segments were excluded from the analysis. Trials to wrong direction or with wrong exertion timing and trials with latencies that were considered too fast or slow were also discarded. Data are epoched and baseline-adjusted to the cue onset for each stage of experiment.

2.4.1. Time domain Analysis. Time domain signals for each subject were averaged and the averages from all subjects were used to find the grand average and the statistical significance of ERPs. The simplified surface Laplacian was applied on channel averages, so that the spatially filtered signal of each channel is obtained by rereferencing to the average of 4 surrounding electrodes (Hjorth, 1991).

2.4.2. Time-Frequency Analysis. To study the time-frequency signatures of signals, we applied scalograms on EEG signals after removing the ERPs from each trial (i.e. removing the phase-locked component of signal).

Using scalograms promotes better time-resolution at higher frequencies and better frequency resolution at lower frequencies and allows additional features to the already well documented spectral changes associated with movement planning and execution to be explored. For time-frequency analysis, continuous Morlet wavelet transform coefficients (Misiti et al., 2007) were calculated using (1):

$$
W(a, b)=\frac{1}{\sqrt{a}} \int_{-\infty}^{+\infty} f(t) \psi^{*}\left(\frac{t-b}{a}\right) d t, \quad \psi(t)=\frac{1}{\sqrt{2 \pi}} e^{-b_{0} t^{2} / 2+j 2 \pi t}
$$

where $W(a, b)$ is the wavelet coefficient at frequency $1 / a, b$ is time, $f(t)$ the signal in time, and * indicates the complex conjugate. To adjust the time-frequency resolution trade-off, the parameter $b_{0}$ was set to $1,0.25$ and 0.1 for frequency ranges $1-20 \mathrm{~Hz}, 21-40 \mathrm{~Hz}$ and $41-50 \mathrm{~Hz}$, respectively. We wrote our own custom codes, along with using Time-Frequency Toolbox (Centre National de la Recherche Scientifique, Paris, France) for comparison and verification of results.

In order to obtain the normalized scalogram (squared wavelet coefficients moduli), the squared coefficients evaluated exactly at the visual cue onset time at each frequency were used as baseline to find the 
normalised relative change in scalogram coefficients at any post-cue time, i.e. the event-related spectral perturbations (ERSP) of each frequency:

$$
\operatorname{ERSP}\left(\frac{1}{a}, b\right)=\frac{\sum_{k=1}^{N}\left(\left\|W_{k}(a, b)\right\|^{2}-\left\|W_{k}(a, 0)\right\|^{2}\right)}{\sum_{k=1}^{N}\left\|W_{k}(a, 0)\right\|^{2}}
$$

where $k$ denotes the trial number from $N$ total and $b=0$ is the cue onset time. It should be noted that the average scalogram values at each frequency band are representative of classic ERD/ERS (Pfurtscheller \& da Silva, 1999) obtained by averaging of the band-passed signal power (Graimann and Pfurtscheller, 2006). The ERSP was used to assess ERD/ERS in ear-lobe-referenced EEG and surface Laplacian EEG which was found for each raw signal segment by re-referencing it to the average of the four surrounding electrodes (Hjorth, 1991).

For analysis of EEG rhythms in $\alpha$ and $\beta$ bands (Sanei \& Chambers, 2007), the average wavelet moduli of each band was used to obtain ERSP. The exact frequency ranges for low- $\alpha$, high- $\alpha$, low- $\beta$ and high- $\beta$ were estimated by inspection of eigenvectors corresponding to the dominant principal components (Jolliffe, 2002) of ERSP data, pooled across electrodes, experiment stages, time, and subjects.

2.4.3. Statistical Analysis. In order to assess the statistical significance of the time-domain potentials and timefrequency distributions, at each time instance the values of ERPs or ERSPs for a specific frequency from all subjects were compared to the corresponding values at the cue onset time (corresponding to 0 value) using Wilcoxon signed-rank non-parametric test. To account for multiple comparisons in several time (and frequency) points and several channels, first, the number of generating sources was estimated by principal component analysis (Jolliffe, 2002). The number of spatial-(spectral)-temporal components that encompassed the knee or knot in the plot of principal components' represented variances and at the same time accounted for $85 \%$ of the variability of the data, plus one, was considered as the number of generating sources. This value was found to be 6 for ERPs and 3 for ERSP. Bonferroni correction was applied accordingly. We used $\alpha=0.05$ as the significance level.

2.4.4. Reporting of ERPs and ERD/ERSs. To better describe and report the signal features, the ERPs or ERD/ERSs that appear earlier than 1.0s after the cue are referred to as "transient" and the constantly present features in the last second of each stage (the time window between 1.0-2.0s for AC and DC and 2.0-3.0s for GO) are referred to as "sustained".

For ear-lobe-referenced ERPs, the peaks between 0 and $1.0 \mathrm{~s}$ after cue onset that had relative and absolute amplitude above $1 \mu \mathrm{V}$ were selected. Those who had a p-value smaller than $\alpha$ at the peak time and in 5 or more neighbour samples around the peak time were reported as ERPs. For surface Laplacian EEG, the threshold amplitude of $0.2 \mu \mathrm{V}$ was used. The sustained potentials were reported if they were significant in $50 \%$ of the 1.0s sustained period. For visual clarity, the ERPs are shown after applying a dual-pass Hann-windowed truncated ideal sinc low-pass filter with cut-off frequency of $5 \mathrm{~Hz}$ which provides zero-lag zero-phase shift filtering.

The transient ERD/ERS at each frequency was reported if it was significant in $25 \%$ of the first $1.0 \mathrm{~s}$ duration after appearance of cue. The sustained ERD/ERS was reported if they were significant in $50 \%$ of the 1.0s sustained period. ERSP signatures that showed an onset time (the first instance after the cue where the 
Page 6 of 33

ERD/ERS becomes significantly different from zero) smaller than the period of the analysis frequency were considered as invalid and were excluded from the report.

\section{Results}

All 8 subjects successfully completed the experiment. In the execution phase, all the subjects had reached the steady state force targets within 2.0s (supplementary material, Figure S1).

\subsection{Ear-Lobe-Referenced Event-Related Potentials}

Figures 3, 4 and 5 show the ear-lobe-referenced ERPs across all electrodes along with the significance levels in preparation (AC), planning (DC) and execution (GO) stages, respectively. The significant positive and negative peaks as well as the sustained potentials are listed in Table 1. An example of consecutive ERPs in the 3 stages of the experiment is shown at $\mathrm{C}_{\mathrm{z}}$ electrode in Figure 6 (top).

AC stage: It can be seen that after AC, there is significant positive peaks at central, frontal-central and parietalcentral electrodes after about 520ms.

DC stage: DC, induces a considerable positivity peak in several of parietal and central-parietal electrodes after about $400 \mathrm{~ms}$ and a negativity peak in several frontal and frontal-central electrodes after about $810 \mathrm{~ms}$. There is also a sustained negativity at frontal-central electrodes.

GO stage: The GO cue induced consecutive positive and negative peaks in frontal and frontal-central electrodes at about $200 \mathrm{~ms}$ and $420 \mathrm{~ms}$, respectively; as well as a late rising positivity in parietal electrodes at about $980 \mathrm{~ms}$ after cue. This is followed by a widespread sustained positivity that appears in central, frontal, frontal-central, parietal and central-parietal electrodes.

The results show that there are ERPs after all visual cues which vary considerably as a function of electrode position and stages of experiment. A notable spatial feature in ear-lobe-referenced EEG is the frequent tendency toward negativity in frontal recordings and negativity in parietal recordings.

\subsection{Surface Laplacian Event-Related Potentials}

Figure 7 shows the surface Laplacian ERPs for 4 selected electrodes $\mathrm{C}_{1}, \mathrm{C}_{2}, \mathrm{FC}_{\mathrm{z}}$ and $\mathrm{CP}_{\mathrm{z}}$, in the preparation (AC), planning (DC) and execution (GO) stages. The complete surface Laplacian ERPs across all electrodes along with the significance levels are provided in supplementary Figures S2, S3 and S4, respectively. The significant positive and negative peaks as well as the sustained potentials are listed in Table 2.

AC stage: It can be seen that after $\mathrm{AC}$, there is a negative peak at $\mathrm{FC}_{\mathrm{z}}$ after $390 \mathrm{~ms}$ followed by positive peaks at $\mathrm{CP}_{\mathrm{z}}$ and $\mathrm{CP}_{1}$ after 484-500ms.

DC stage: DC induces a positivity peak at $\mathrm{CP}_{\mathrm{z}}$ after $436 \mathrm{~ms}$ which is followed by a negative peaks at $\mathrm{FC}_{\mathrm{z}}, \mathrm{FC}_{2}$. GO stage: The $\mathrm{GO}$ cue induced positive peaks at $\mathrm{CP}_{1}$ and $\mathrm{CP}_{\mathrm{z}}$ after $170 \mathrm{~ms}$ and $515 \mathrm{~ms}$, as well as negative peaks after 394-406ms at $\mathrm{FC}_{1}$ and $\mathrm{FC}_{\mathrm{z}}$. Importantly, this is followed by a sustained positivity at $\mathrm{C}_{1}$.

The general positivity and negativity patterns in Laplacian ERPs are similar to ear-lobe referenced ERPs, but considerably local. Laplacian EEG shows that the motor related activity is mainly observed in $\mathrm{CP}_{\mathrm{z}}, \mathrm{CP}_{1}, \mathrm{FC}_{\mathrm{z}}$, and $\mathrm{FC}_{1}$ electrodes in form of positive and negative peaks. Sustained potentials are mostly vanished in Laplacian EEG, except for a non-significant negativity during planning at $\mathrm{FC}_{\mathrm{z}}$ and $\mathrm{C}_{1}$ and a non-significant positivity during execution at $\mathrm{C}_{1}$. The other observation is the relatively symmetric and mid-line-centric activity 
during AC (preparation) and to some extent DC (planning) stages, while the activity in GO stage (execution) is asymmetric with bolder contralateral activity. The early and late negativity and positivity components in planning (DC) stage can be associated with the early and late components of CNV (Cui et al., 2000; Gomez et al., 2003), especially due to their spatial map matching. Similarly, in the execution stage (GO) the early negative and late positive components can be associated with earlier and later components of MRPs (Hink et al., 1983; Oda et al., 1996; Slobounov \& Ray, 1998).

\subsection{Ear-Lobe-Referenced Event-Related (De-)Synchronizations}

Figure 6 (bottom panel) shows representative consecutive ERD/ERS in electrode $C_{z}$, during preparation (AC), planning (DC) and execution (GO) stages. The complete maps of significant ERD/ERS across all electrodes are provided in supplementary Figures S5, S6 and S7, respectively. Table 3 lists the frequency ranges for significant ERD or ERS in 5 selected electrodes $\mathrm{C}_{\mathrm{z}}, \mathrm{C}_{3}, \mathrm{C}_{4}, \mathrm{P}_{\mathrm{z}}$ and $\mathrm{F}_{\mathrm{z}}$. The complete data for all electrodes are listed in supplementary material, Table S1.

AC stage: It can be seen that after AC, there is transient low $\alpha(8-9 \mathrm{~Hz})$ ERD at $\mathrm{C}_{4}$. The ERD in low $\beta$ band is transient $(16-20 \mathrm{~Hz})$ in $\mathrm{C}_{\mathrm{z}}, \mathrm{C}_{3}, \mathrm{C}_{4}$ and $\mathrm{F}_{\mathrm{z}}$. There is also a sustained $3 \mathrm{~Hz}$ ERD at $\mathrm{C}_{4}$ and $\mathrm{F}_{\mathrm{z}}$. DC stage: DC induces transient low $\alpha(8 \mathrm{~Hz})$ ERD at $\mathrm{C}_{\mathrm{z}}, \mathrm{C}_{3}, \mathrm{P}_{\mathrm{z}}$ and $\mathrm{F}_{\mathrm{z}}$. Other transient ERDs appear in low $\beta$ band at $\mathrm{C}_{\mathrm{z}}$ and $\mathrm{C}_{3}(15-21 \mathrm{~Hz})$ and also at $\mathrm{F}_{\mathrm{z}}(26-29 \mathrm{~Hz})$. The notable sustained activity is $8 \mathrm{~Hz}$ ERD at $\mathrm{C}_{\mathrm{z}}$. $G O$ stage: The $\mathrm{GO}$ cue induced transient $\theta$ band $\mathrm{ERD}(6-7 \mathrm{~Hz})$ at $\mathrm{C}_{3}, \mathrm{C}_{4}$ and $\mathrm{P}_{\mathrm{z}}$. There is transient low $\alpha$ ERD at $\mathrm{P}_{\mathrm{z}}, \mathrm{C}_{\mathrm{z}}, \mathrm{C}_{3}$, and $\mathrm{C}_{4}$, and transient high $\alpha$ ERD only at $\mathrm{C} 3$ and $\mathrm{P}_{\mathrm{z}}$. The electrodes $\mathrm{C}_{\mathrm{z}}, \mathrm{C}_{3}, \mathrm{C}_{4}$ and $\mathrm{P}_{\mathrm{z}}$ also show transient low $\beta(17-21 \mathrm{~Hz})$ ERD to different extents. There is also sustained ERD at $\mathrm{P}_{\mathrm{z}}$ between 3-9Hz which extends to $\mathrm{C}_{4}$. The other sustained activity is in the form of ERD between $10-15 \mathrm{~Hz}$ at $\mathrm{F}_{\mathrm{z}}$.

The onset time of ERD/ERS was on average $353 \mathrm{~ms}( \pm 157 \mathrm{~ms} \mathrm{SD})$ within the range of $52 \mathrm{~ms}$ and $750 \mathrm{~ms}$ and heavily depended on the channel location $(\mathrm{p}<0.05)$, frequency $(\mathrm{p}<0.10)$ and cue type $(\mathrm{p}<0.10)$, when tested by 3-way ANOVA.

The ERD/ERS features are very similar across recording electrodes. Transient $\beta$ band ERD is seen after all cues. In addition, transient low $\alpha$ band ERD after AC and transient and sustained low $\alpha$ were observed after DC. In the GO stage, i.e. during force development and maintenance, transient and sustained ERD is observed in both low and high $\alpha$ band ( $\mu$ rhythm ERD) and in high $\theta$ band. These ERDs are spread over scalp and are slightly bolder over contralateral motor areas.

\subsection{Surface Laplacian Event-Related (De)-Synchronizations}

Figure 7 shows surface Laplacian ERD/ERS for 4 selected electrodes $\mathrm{C}_{1}, \mathrm{C}_{2}, \mathrm{FC}_{\mathrm{z}}$, and $\mathrm{CP}_{\mathrm{z}}$ during preparation (AC), planning (DC) and execution (GO) stages. The complete maps of significant surface Laplacian ERD/ERS across all electrodes are provided in supplementary Figures S8, S9 and S10, respectively. Table 4 lists the frequency ranges for significant ERD or ERS in the 5 selected electrodes $C_{z}, C_{1}, C_{2}, C_{z}$ and $F_{z}$ that could well represent ERD/ERS patterns in Laplacian referencing. The complete data for all electrodes are listed in supplementary material, Table $\mathrm{S} 2$.

AC stage: It can be seen that after $\mathrm{AC}$, there is transient $\theta$ ERS at $\mathrm{FC}_{\mathrm{z}}$, while $\mathrm{CP}_{\mathrm{z}}$ shows $\theta$ ERD (Figure $\mathrm{S} 8$ and Table 4). The transient $\alpha$ ERD occurs in low and high $\alpha$ at $\mathrm{FC}_{\mathrm{z}}$, but only in low $\alpha$ at $\mathrm{CP}_{\mathrm{z}}$. There is low $\beta$ transient 
ERD at $\mathrm{CP}_{\mathrm{z}}$ and $\mathrm{C}_{1}$, as well as high $\beta$ ERD at $\mathrm{FC}_{\mathrm{z}}$. The sustained observed ERD is in $2-3 \mathrm{~Hz}$ range at $\mathrm{C}_{\mathrm{z}}, \mathrm{C}_{1}$ and $\mathrm{CP}_{\mathrm{z}}$, which extends to sustained $\theta \mathrm{ERD}$ at $\mathrm{CP}_{\mathrm{z}}$.

DC stage: DC induces a transient ERS in 3-7Hz to different extents at $\mathrm{C}_{\mathrm{z}}$ and $\mathrm{FC}_{\mathrm{z}}$ and $\mathrm{C}_{1}$. $\mathrm{A}$ transient low $\alpha$ ERD happens at $\mathrm{C} 1, \mathrm{FC}_{\mathrm{z}}$ and $\mathrm{CP}_{\mathrm{z}}$, but a high $\alpha(12 \mathrm{~Hz}) \mathrm{ERS}$ at $\mathrm{C}_{2}$. There is a transient $\beta$ ERD primarily at $\mathrm{C}_{1}$ which also extends to $\mathrm{C}_{\mathrm{z}}$ and $\mathrm{FC}_{\mathrm{z}}$. The sustained $\mathrm{ERD}$ is a wide-spread 2-3Hz ERD in all electrode but also a sustained low $\alpha$ ERD at $\mathrm{C}_{1}$.

GO stage: The $\mathrm{GO}$ cue induced transient $\theta$ band $\mathrm{ERS}(5-6 \mathrm{~Hz})$ at $\mathrm{C}_{1}, \mathrm{FC}_{\mathrm{z}}$ and $\mathrm{CP}_{\mathrm{z}}$. There is transient ERD in low $\alpha$ at $\mathrm{FC}_{\mathrm{z}}$, in high $\alpha$ at $\mathrm{C}_{1}$, and in both low and high $\alpha$ at $\mathrm{C}_{\mathrm{z}}, \mathrm{C}_{2}$, and $\mathrm{CP}_{\mathrm{z}}$. The electrodes $\mathrm{C}_{\mathrm{z}}, \mathrm{C}_{1}, \mathrm{C}_{2}, \mathrm{FC}_{\mathrm{z}}$, and $\mathrm{CP}_{\mathrm{z}}$ all show transient low and high $\beta$ ERD to different extents. Additionally, the transient ERD extends to $\gamma$ at $\mathrm{C}_{1}$, $\mathrm{C}_{2}$ and $\mathrm{CP}_{\mathrm{z}}$. There is also sustained ERD in $2-5 \mathrm{~Hz}$ at $\mathrm{C}_{\mathrm{z}}, \mathrm{C}_{1}, \mathrm{C}_{2}, \mathrm{FC}_{\mathrm{z}}$, and $\mathrm{CP}_{\mathrm{z}}$ to different extents. The other sustained activities are in the form of $\alpha \mathrm{ERD}$ at $\mathrm{C}_{1}, \mathrm{C}_{2}$ and $\mathrm{FC}_{\mathrm{z}}$, as well as high $\beta$ ERD at $\mathrm{C}_{1}$.

The dominant ERD/ERS features include transient and sustained $\alpha$ and $\beta$ ERD. The transient $\alpha$ ERD occurs after all cues in most electrodes, except the ipsilateral motor area where little ERD (and even ERS) is observed. While the sustained $\alpha$ ERD can be seen in all major areas during execution (GO), the only planningtime sustained $\alpha$ ERD appears in contralateral motor area. The transient $\beta$ ERD occurs after all cues, except in contralateral and parietal areas that occurs only after execution cue (GO).

\section{Discussion}

\subsection{Comparison to Previous EEG and ECoG Studies}

As expected we observed ERPs and ERD/ERS, similar to those observed in movement tasks or motor imagery. The EEG signatures associated with each stage of the experimental paradigm, preparation, planning and execution stages are similar to those seen in movement or motor imagery tasks (Caldara et al., 2004; Neuper et al., 2006).

There is considerable documented research about EEG correlates of isometric force generation or movement, but most of them approach the EEG or MEG signal from different viewpoints such as: corticomuscular coherence (Chakarov et al., 2009; Conway et al., 1995; Salenius and Hari, 2003; Schoffelen et al., 2008); reflection of arm (Siemionow et al., 2000), finger (Oda et al., 1996; Shibata et al., 1997; Slobounov et al., 2002) or foot (do Nascimento et al., 2005, 2006) force magnitude in MRPs; classifying force or rate of torque development in real or imaginary isometric tasks (Gu et al., 2009; do Nascimento and Farina, 2008; Romero et al., 2000). We now underline the reports more closely related to our study, i.e. the ERP and ERD/ERS patterns during motor tasks:

Time Domain: MRP studies during movement tasks (Colebatch, 2007) and isometric tasks include a wide range from self-paced and reaction-time-studies to instruction-delay or pre-cueing studies with different experimental conditions electrode referencing methods. We briefly describe the key similarities and differences of our results compared to the aforementioned studies: 1 . Similar sustained negativity in motor planning and sustained positivity in motor execution over central motor areas (Ulrich et al., 1998; Wilke and Lansing, 1973). 2. Similar trend of positivity in parietal recordings and negativity in frontal recordings in many ERP waveforms (Jahanshahi et al., 1995; Leuthold and Jentzsch, 2009). 3. Different and more complex waveforms and largely different waveform timings due to unpredictable cues in different stages in our experiment and absence of many waveforms in previous studies due to different experiment design (Leuthold and Jentzsch, 2009; do Nascimento 
Page 9 of 33

et al., 2005, 2006; Slobounov and Ray, 1998; Ulrich et al., 1998). 4. Different spatial variation of the observed features due to different EEG referencing and different experiment design (MacKay and Bonnet, 1990; Wilke and Lansing, 1973).

Time-Frequency Features: There are relatively common trends of activity during various movements and motor imagery tasks (Graimann and Pfurtscheller, 2006; Waldert et al., 2009). Magnetoencephalography (MEG) and EEG signatures of arm movements (Waldert et al., 2008), as well as electrocorticography (ECoG) signatures (Waldert et al., 2009) show ERD in $\alpha$ and $\beta$ bands with most of the reported ERD on contralateral and to some extent ipsilateral motor areas. This is in agreement with general expectations of movement related ERD/ERS (Graimann and Pfurtscheller, 2006; da Silva, 2006; Srinivasan et al., 2006). The ECoG signatures (ERD/ERS) of non-directional sustained isometric contractions of body parts over several regions of brain (Crone et al., 1998a,b) also show notable trends: There is $\alpha$ and $\beta$ band ERD in transient and (to lesser extent) in sustained form over motor areas, in both ipsilateral and especially contralateral sides. The low and mid $\gamma$ ERS has also been reported over contralateral motor areas. In the execution stage, we observed the same overall ERD pattern for $\alpha$, and $\beta$ compared to both EEG movement studies and ECoG isometric studies. An observed difference is the dependence of the laterality of $\alpha$ and $\beta$ band ERD on planning/execution stage. While the bolder contralateral activity during planning matched the mentioned movement studies (reporting combined planning and execution stages), the $\alpha$ and $\beta$ band ERD during execution was stronger in the ipsilateral areas. This dominant ipsilateral ERD during the execution stage was not due to cortical pre-activation that may lead to different baseline power for ERSP calculation in different regions. When the ERSP in all stages were referenced and normalised to the same baseline power at AC onset time (Figure S11), the dominant ipsilateral ERD is not diminished. However, this difference between contralateral $\left(\mathrm{C}_{1}\right)$ and ipsilateral $\left(\mathrm{C}_{2}\right)$ Laplacian ERD levels was not statistically significant for any execution time, frequency band and normalisation method when tested by paired t-test $(\mathrm{p}>0.05)$. Although a concluding interpretation needs further evidence, differences in sensorimotor processing of sensory information, extrinsic coordinates, direction and muscle activity in different stages of different tasks can be responsible for this. Additionally, different hemispheric specialization for isometric tasks vs. movement tasks (Schaafer et al., 2009; Mani et al., 2013) as well as transient and declining cortical contributions (vs. more persistent and sustained spinal contributions) in constant-force isometric tasks (Shalit $e t$ $a l ., 2012)$ may be responsible in this regard. In low $\gamma$ band $(30-50 \mathrm{~Hz})$, the movement studies report ERD, while the sustained contraction ECoG study (Crone et al., 1998a,b) reports ERS. In our study, the ERD/ERS in $\gamma$ band was not significant in general; however, in some subjects we observed ERS in parietal regions $\left(\mathrm{P}_{\mathrm{z}}\right)$ and ERD in other regions including ipsilateral and contralateral motor regions. The reported ERD in all bands during isometric foot force development in $\mathrm{C}_{\mathrm{z}}$ (Masakado and Nielsen, 2008), is confirmed by our results of $\alpha$ and $\beta$ bands. In comparison to another similar instruction-delay MEG study (Tzagarakis et al., 2010), we see two main similarities: (1) high $\beta$ ERD is observed in contralateral motor and pre-motor area with extension to neighbouring regions, which was then shown to originate mostly from pre-Rolandic area, (2) the occurrence of $\beta$ ERD after both planning and execution cues, where the first ERD onset in $\beta$ range $(85.5 \mathrm{~ms})$, and $\beta$ ERD peaktime after planning cue (DC) at $\mathrm{C}_{3}(485 \mathrm{~ms})$, are comparable to the corresponding reported values of $120 \mathrm{~ms}$ and $\sim 350-500 \mathrm{~ms}$ by Tzagarakis et al. (2010). The $\beta$ ERD onset time is also comparable to the $113 \mathrm{~ms}$ value of the local field potential (LFP) study of Zhang et al. (2008). In a more general perspective, the presence of $\beta$ ERD 
Page 10 of 33

after both planning and execution cues, especially on contralateral motor areas are also similar to studies on precued finger-press movement tasks (Doyle et al., 2005).

We can conclude that readiness and planning stages share many common (and mostly transient) timefrequency features in isometric exertions. However, there are features specific to each step. Execution can be described to have the most prominent ERD in the widest range of frequencies compared to preparation and planning. In all stages patterns are close to movement ERD/ERS.

\subsection{Potential Neural Processing Mechanisms}

The significance of this study is the association of function (preparation, planning and execution) in motor tasks with EEG signatures and the generating sources. We may infer the potential neural processing sources and their function from the observed ERPs and ERD/ERSs.

ERPs mostly reflect the activity of superficial cortical circuitries as the Laplacian ERPs seem to represent the majority of potentials observed in ear-lobe-referenced ERPs with higher locality and no major ERP remains unrepresented in Laplacian ERPs. The sustained lasting potentials, though partially localised in Laplacian EEG seem to come from slightly deeper sources or circuits. Taking into account the anatomical correlates of the most active electrodes (Koessler et al., 2009; Okamoto et al., 2004), i.e. $\mathrm{CP}_{\mathrm{z}}(\mathrm{PC}), \mathrm{C}_{1}$ (M1/PM) and $\mathrm{FC}_{\mathrm{z}}$ and $\mathrm{FC}_{1}(\mathrm{SMA} / \mathrm{PM})$, along with the observed Laplacian ERPs, we may draw conclusions about the neural processing mechanisms. The supplementary motor areas and premotor areas get activated symmetrically in preparation of isometric task reflected as positive ERP waveforms. SMA/PM areas and parietal cortex show symmetrical activity with sequentially negative and positive ERP waveforms during direction-dependent planning which can imply a communication between the 2 areas. During actual execution of isometric tasks, i.e. actual force generation, in addition to symmetric activity in SMA/PM and parietal cortex (as in planning), PM/M1 areas show additional contralateral activity reflected in ERP negative waveforms. Importantly, during the force maintenance the M1 area remains active which is reflected in the sustained positivity. These activities are from superficial cortical sources.

We may compare our ERPs results with single cell recording studies (Cisek and Kalaska, 2005), although usually performed on primates and during movements (vs. isometric tasks) and the fact that the firing rate activity measures have not been translated to equivalent ERPs or ERD/ERSs. These studies show that during movement execution both primary motor cortex (M1) and premotor cortex (PM) show transient activity, but only PM shows activities (in transient form), when AC and especially DC are presented to primates. Dorsal PM areas show both ipsilateral and strong contralateral activity and this activity is maintained during the execution of movement. In M1, activity is seen only during motor execution and not planning. The activity in contralateral side is considerably higher than ipsilateral side (Cisek et al., 2003). Isometric studies, mostly address M1 activity during task execution (Sergio et al., 2005). There are both transient and sustained activities during force development and maintenance. There are few studies that address PM activity in isometric tasks and practically no results for planning stage of isometric exertions (Ashe, 1997; Personal Communication, John. F. Kalaska). Our findings on surface Laplacian ERPs show that preparation and planning involve symmetric (ipsilateral and contralateral) frontal-central (SMA/PM) and parietal areas (PC). Also, the activity during execution is mostly contralateral in central (M1) and frontal-central (M1/PM) regions. This is in good agreement with invasive studies on primates and informs of similar neural processing in humans. The observed laterality of 
Page 11 of 33

ERPs is also compatible with the view of relatively direct role of contralateral motor cortex (Soteropoulos et al., 2011) in execution of tasks and participation of both ipsilateral and contralateral hemispheres in preparation and planning (Schaal et al., 2004). These findings suggest that PM/SMA is active in early preparation; PC activity is added for direction-dependent processing; and M1 activity is mostly related to generation of descending neural motor commands.

The ERSP patterns are present both in ear-lobe-reference EEG and in Laplacian EEG, but with different distributions of spatial intensities: in preparation ERDs are contralateral which are pronounced in central motor areas with ear-lobe referencing, while pronounced over more frontal and parietal areas with Laplacian filter; in planning the contralateral central motor and parietal areas show overall similar ERD with both referencing methods; in execution the ERDs are mostly bilateral which are more pronounced in frontal and especially parietal areas, while Laplacian gives more accentuation to central and ipsilateral motor areas. These patterns suggest the involvement of several different deep and superficial cortical sources in brain that are considerably more distributed and less focal compared to ERP sources. The contribution of deep sources to ERD, is in line with current literature on ERD/ERS generation fundamentals and mechanisms (Pfurtscheller, 2006; da Silva, 2006) that ERD/ERS is generated by deeper circuitries such as thalamo-cortical loops (Pfurtscheller, 2006; da Silva, 2006), while the contribution of superficial sources to ERD is supported by other fMRI studies (Cooreman et al., 2011) that attribute them primarily to superficial cortical activities.

In the 3 stages of the experiment, the ERPs and ERD/ERSs appear to have similar dominant proportions of transient (AC and DC) vs. sustained (DC and GO) activity in different stages (See Figures 3-5 and S2-S10). However, while the ERPs are mid-line centric in preparation and planning but contralateral in execution; the ERD/ERSs are contralateral in the AC and DC stages and more mid-line-centric in the GO stage (See figure 7). These observation and potentially different sources of ERPs and ERD/ERSs, as discussed above, make it difficult to establish a strong association between the two. Future studies, using accurate source localization can help in this regard.

Most importantly to mention, all the above-mentioned time or time-frequency signatures did not depend on physical position, displacement, velocity or trajectory of the limb in extrinsic coordinates, nor on the sensory information changes that could have affected the somatosensory cortex and then the other motor areas. They are therefore originated from motor preparation, direction-dependent information of planning and motor command generation.

\subsection{Debates}

4.3.1. On Averaging and Normalisation. Rest-time EEG is affected by background cognitive processing, attentiveness (Compton et al., 2011) and other artefacts. When used for normalisation, this uncertainty affects the resultant normalized scalogram and identification of feature as ERD or ERS. In some cases, we observed significant ERD in the majority of subjects, but a few subjects displayed significant ERS activity. This different observation in the minority can be because of inter-individually different motor processing, but we suggest that the EEG normalisation inaccuracy can be the source of variance in results. Improved normalisation techniques and spectral techniques can contribute to higher consistency across subjects.

4.3.2. Source and nature of the observed EEG activity. It is important to take into account the potential visual stimulative effects of the experiment. The distance between the subject and monitor screen limits the visual 
angle to 5 degrees and minimizes the eye-movement and movement artefacts. We also rejected all the trials with traces of eye movements and found no trace of eye movements in multichannel EEG of accepted trials.

We should emphasize that the task is a visuo-motor task because of the roles of cues and real time feedback of force on the screen. Consequently we cannot completely remove the visual processing from motor aspects of the task. However, it is noteworthy that the ERPs and ERD/ERSs observed after the cues are because of the attentional roles of the cues in the planning and execution of the requested task and not the visual appearance of cues per se. Unattended visual cues show no time and time-frequency changes in EEG (Valsan, 2007), even in case of moving cues (Guo et al., 2008). This attentional role (especially reflected in the $\beta$ ERD, about $100 \mathrm{~ms}$ after the cues), can be attributed to orienting reflex in general (Pfurtscheller et al., 2013); but more specifically, this attention is known to engage the motor-related areas in the context of a motor task (Tzagarakis et al., 2010; Pfurtscheller et al., 2013). In short, the visual components -if any- get their identity in the context of the visuo-motor task. Additionally, we observed that ERPs and ERD/ERS patterns are not of higher intensity in occipital areas over visual cortex $\left(\mathrm{O}_{\mathrm{z}}\right.$ and $\mathrm{I}_{\mathrm{z}}$ electrodes $)$ and EEG signatures in these electrodes are not spread to the reported electrodes. Nevertheless, we choose the term ERP over MRP or visualevoked potentials (VEP) for the observed potentials, to avoid potential over-interpretation and to account for the complex nature of these potentials. Following this discussion, we may emphasise that in the isometric tasks subjects were exerting force without moving their arm. Therefore the observation of self-movement (Pineda, 2005; Hari, 2006) could not have induced the observed EEG signatures. Furthermore, subjects were paying attention to the CRT display and their arm was not in their direct field of view.

As we studied the averaged results for all directions, the study does not highlight the spatio-temporal features specific to each direction. This makes the task similar to more complicated arm tasks where all the muscles are active at the same time. While motor parameters such as direction and level of exerted force affect the signal amplitude, the waveforms or essential ERD/ERS characteristics remain unchanged (Leuthold and Jentzsch, 2009; do Nascimento et al., 2005, 2006; Valsan, 2007; Waldert et al., 2009). Additionally, in analysing of the inter-class difference of ERPs and ERD/ERS (not presented here), no significant difference was found (Nasseroleslami, 2013).In short, the lack of significant direction-dependency for ERPs and ERD/ERSs suggests that neither the spatial features (e.g. differences in specific electrodes) nor the temporal features (e.g. peak ERD value or time, as discussed in Pfurtscheller et al., 2013) of ERD/ERS significantly depends on direction. Consequently, the reported features hold for all directions. This direction-independence in the EEG of an isometric task was unexpected, considering the presence of direction-dependency in movement EEG/ECoG (Waldert et al., 2009; Pfurtscheller et al., 2013) and in single cell activity of both movement and isometric exertions (Georgopoulos et al., 1982; Sergio et al., 2005).

It is useful to underline the potential role of EMG artefacts, once more. With the careful recording, conservative rejection of artefacts and careful statistical analysis we minimized the chance of EMG contamination. The logical link between Laplacian and ELR results, lack of gamma band ERS in the reported data, as well as similarity of preparation and execution stage EEG features (one with less and one with more contamination chance) suggest that the impact of EMG artefacts have been minimal. However, the gold standard for true EMG-free recording (including those from head muscles) would be the use of neuromuscular blockade (See Muthukumaraswamy, 2013, for a review). 
4.3.3. Variability. As mentioned earlier, the previous literature about ERP and ERD/ERS includes various experimental setups, different paradigms (instruction delay, reaction-time, self-paced), different involved body part (arm, fingers, and foot), different tasks (sustained contraction, reaching, and manipulation) and different task parameters. Consequently, the comparison of our results to those reported in the literature should be considered as approximate and not as exact validation. This is of special importance when variability in the observed EEG has been reported (Graimann and Pfurtscheller, 2006; da Silva, 2006) and also by taking into account the different neuro-circuitry and neuro-computations responsible for different motor tasks in the literature (Jordan and Wolpert, 1999; Shadmehr and Wise, 2005). 4.4. Applications and Future Research Perspectives

The features identified in this study relate to isometric planning and execution and therefore present additional insight into the EEG signatures previously described for point to point movements and those generating joint/limb displacement. For clinical applications, it is likely that isometric training tasks without the need for limb displacement (reaching, pointing and manipulation tasks) may provide a paradigm that is simpler to adapt to the needs of individual patients, during early stages of BCI-aided rehabilitation. Investigation of the observed signatures in acute stroke and other central nervous system trauma conditions will be of interest in this respect.

Future work is expected to apply source localisation techniques (Srinivasan et al, 2006), network analysis (Lindsay and Rosenberg 2011) and also more accurate time-frequency representations (Boashash, 2003; Cohen, 1995; Hlawatsch \& Auger, 2008) to localize the ERD/ERS sources more accurately in time and frequency. However, given that a degree of inter-subject variability exists in the sample presented here there is a need for caution in interpretation. Further studies aimed at determining the degree of inter-subject variability of features of interest are therefore warranted. Similarly, the robustness of the reported observations will be required to be explored through the use of a range of normalization techniques and the study of subject groups with motor or sensory impairments.

The other immediate research question will be the role of direction in the context of previous force parameter decoding studies (do Nascimento and Farina, 2008), similar to studies on movement direction (Waldert et al., 2008) or trajectory decoding (Bradberry et al., 2010; Schalk et al., 2007). The potential of decoding task parameters such as intended direction of effort in planning and execution from EEG, will be the focus of our further studies.

\section{Conclusions}

Instruction-delay and other complex protocols in movement and isometric tasks together with EEG analysis, proves to be a useful tool for study of human motor function. Isometric tasks in preparation, planning and execution stages show statistically significant ERP and ERD/ERS patterns very similar to movement and motor imagery that do not depend on the planned extrinsic coordinate change or change in muscle lengthdependent ascending sensory information. Preliminary interpretation of the activated brain regions (SMA, PM, M1, PC) and their laterality matches the current understanding of primate motor function from invasive recordings. The functional role of these brain regions are reflected in ERPs (frontal-central negative and centralparietal positive waveforms) originating from superficial cortical areas, sustained potentials (planning negativity and execution positivity), and the ERSPs (mostly $\beta$ and $\mu$ ERD) reflect the processing in both deep and 
Page 14 of 33

superficial brain regions. Further investigating the reflection of the activity of different brain regions in EEG, as a function of different task stages and parameters will be of benefit for clinical studies and for neurorehabilitation research.

\section{Acknowledgement}

The assistance of students, research staff, and technical staff of Department of Biomedical Engineering, University of Strathclyde, in data collection and discussions on the manuscript is highly appreciated. The financial support from Glasgow Research Partnership in Engineering (GRPE) needs special acknowledgement. The authors are thankful to anonymous reviewers for comments and suggestions on previous and current versions of the manuscript.

\section{Funding and Conflict of Interest}

This work was supported by Scottish Funding Council (SFC) through Glasgow Research Partnership in Engineering (GRPE). The funding body was not involved in the design of experiment, data collection and analysis, interpretation of results and preparation and submission of the manuscript.

The authors declare that they have no conflict of interest.

\section{Abbreviations}

AC: Attention Cue

DC: Direction Cue

CNV: Contingent Negative Variation

ECoG: Electrocorticogram

EEG: Electroencephalogram

ERD: Event-Related De-synchronisation

ERP: Event-Related Potentials

ERS: Event-Related Synchronisation

ERSP: Event-Related Spectral Perturbation

M1: Primary Motor Cortex

MEG: Magnetoencephalography

MRP: Motor-Related Potential

PM: Premotor Cortex

RC: Rest Cue

PC: Parietal Cortex

SMA: Supplementary Motor Area 


\section{Figures Captions:}

Figure 1. (a) Schematic of the experiment: subjects exert force in horizontal plane to 4 different directions according to the visual cues on the monitor at about $175 \mathrm{~cm}$ distance. (b) The manipulandum used in the experiment. The gear knob (1) is grabbed by the subject to exert force. The knob is attached to the sensor (3) via a top-plate connector (2) and is attached to the base (5) via bottom-plate connector (4). The assembly and the seat (7) are fixed to the support (6). An elbow and arm rest (8) is used to support the arm's weight.

Figure 2. Sequence of visual cues and timings (indicated in parentheses). The cues (from left to right): 0. Rest, where subject takes no action or planning. 1. White screen preceding the attention cue (RC). 2. Attention cue (AC), as a black circle that appears in the middle of screen and tells the subject to be prepared for planning/exertion. 3. Directional cue (DC), as another black circle in one of the 4 random directions and instructs the subject to plan for exertion in the specified direction in the next stage (Subject takes no physical action). 4. GO signal (GO), the middle black circle changes to red and tells the subject to start the isometric exertion toward the indicated direction in the last stage. Simultaneously, the subject sees the direction and magnitude of the exerted force as an orange centre-out line. 5. End of trial and start of next trial.

Figure 3. Ear-lobe-referenced ERP $(\mu \mathrm{V})$ across scalp, averaged across 8 subjects during preparation (AC) stage. Thick lines show significant ERP at $\alpha=0.05$ after correction for multiple comparisons.

Figure 4. Ear-lobe-referenced ERP ( $\mu \mathrm{V})$ across scalp, averaged across 8 subjects during planning (DC) stage. Thick lines show significant ERP at $\alpha=0.05$ after correction for multiple comparisons.

Figure 5. Ear-lobe-referenced ERP $(\mu \mathrm{V})$ across scalp, averaged across 8 subjects during execution (GO) stage. Thick lines show significant ERP at $\alpha=0.05$ after correction for multiple comparisons

Figure 6. Ear-lobe-referenced ERP (top) and significant ERSPs (bottom) at electrode $\mathrm{C}_{\mathrm{z}}$ averaged across 8 subjects during preparation (AC), planning (DC) and execution (GO) stages. Significant at $\alpha=0.05$ after correction for multiple comparisons.

Figure 7. Surface Laplacian ERP (black), $\alpha$-band ERD/ERS (red) and $\beta$-band ERD/ERS (blue) at 4 selected electrodes $\mathrm{C}_{1}, \mathrm{C}_{2}, \mathrm{FC}_{\mathrm{z}}$ and $\mathrm{CP}_{\mathrm{z}}$ averaged across 8 subjects during preparation (AC), planning (DC) and execution (GO) stages. Significant at $\alpha=0.05$ after correction for multiple comparisons. 


\section{References}

Ashe, J. (1997, June). Force and the motor cortex. Behav Brain Res, 86(1), 1-15.

Babiloni, C., Carducci, F., Cincotti, F., Rossini, P. M., Neuper, C., Pfurtscheller, G., \& Babiloni, F. (1999, December). Human movement-related potentials vs desynchronization of EEG alpha rhythm: a highresolution EEG study. Neuroimage, 10(6), 658-665.

Birbaumer, N., Murguialday, A. R., \& Cohen, L. (2008, December). Brain-computer interface in paralysis. Curr Opin Neurol, 21(6), 634-638.

B. Boashash (Ed.). (2003). Time-frequency signal analysis and processing: a comprehensive reference. Elsevier.

Bradberry, T. J., Gentili, R. J., \& Contreras-Vidal, J. L. (2010, March). Reconstructing three-dimensional hand movements from noninvasive electroencephalographic signals. J Neurosci, 30(9), 3432-3437.

Brainard, D. H. (1997). The psychophysics toolbox. Spat Vis, 10(4), 433-436.

Caldara, R., Deiber, M.-P., Andrey, C., Michel, C. M., Thut, G., \& Hauert, C.-A. (2004, December). Actual and mental motor preparation and execution: a spatiotemporal ERP study. Exp Brain Res, 159(3), 389-399.

Chakarov, V., Naranjo, J. R., Schulte-Mönting, J., Omlor, W., Huethe, F., \& Kristeva, R. (2009, August). Betarange EEG-EMG coherence with isometric compensation for increasing modulated low-level forces. $J$ Neurophysiol, 102(2), 1115-1120.

Cisek, P., Crammond, D. J., \& Kalaska, J. F. (2003, February). Neural activity in primary motor and dorsal premotor cortex in reaching tasks with the contralateral versus ipsilateral arm. J Neurophysiol, 89(2), 922942.

Cisek, P., \& Kalaska, J. F. (2004, October). Neural correlates of mental rehearsal in dorsal premotor cortex. Nature, 431(7011), 993-996.

Cisek, P., \& Kalaska, J. F. (2005, March). Neural correlates of reaching decisions in dorsal premotor cortex: specification of multiple direction choices and final selection of action. Neuron, 45(5), 801-814.

Cohen, L. (1995). Time-frequency analysis. Prentice Hall Signal Processing Series. Prentice Hall PTR.

Colebatch, J. G. (2007, April). Bereitschaftspotential and movement-related potentials: origin, significance, and application in disorders of human movement. Mov Disord, 22(5), 601-610.

Compton, R. J., Arnstein, D., Freedman, G., Dainer-Best, J., \& Liss, A. (2011, May). Cognitive control in the intertrial interval: evidence from EEG alpha power. Psychophysiology, 48(5), 583-590. doi:10.1111/j.1469-8986.2010.01124.X

Conway, B. A., Halliday, D. M., Farmer, S. F., Shahani, U., Maas, P., Weir, A. I., \& Rosenberg, J. R. (1995, December). Synchronization between motor cortex and spinal motoneuronal pool during the performance of a maintained motor task in man. J Physiol, 489 ( Pt 3), 917-924.

Cooreman, C., Sclocco, R., Tana, M. G., Vanderperren, K., Visani, E., Panzica, F., ... Bianchi, A. M. (2011). Bold correlates of alpha and beta EEG-rhythm during a motor task. In Proc. 5th int neural engineering (ner) ieeelembs conf (pp. 25-28). doi:10.1109/NER.2011.5910481

Crone, N. E., Miglioretti, D. L., Gordon, B., \& Lesser, R. P. (1998, December). Functional mapping of human sensorimotor cortex with electrocorticographic spectral analysis. ii. event-related synchronization in the gamma band. Brain, 121 ( Pt 12), 2301-2315.

Crone, N. E., Miglioretti, D. L., Gordon, B., Sieracki, J. M., Wilson, M. T., Uematsu, S., \& Lesser, R. P. (1998, December). Functional mapping of human sensorimotor cortex with electrocorticographic spectral analysis. i. alpha and beta event-related desynchronization. Brain, 121 ( Pt 12), 2271-2299.

Cui, R. Q., Egkher, A., Huter, D., Lang, W., Lindinger, G., \& Deecke, L. (2000, October). High resolution spatiotemporal analysis of the contingent negative variation in simple or complex motor tasks and a nonmotor task. Clin Neurophysiol, 111(10), 1847-1859.

da Silva, F. H. L. (2006). Event-related neural activities: what about phase? Prog Brain Res, 159, 3-17. 
do Nascimento, O. F., \& Farina, D. (2008, November). Movement-related cortical potentials allow discrimination of rate of torque development in imaginary isometric plantar flexion. IEEE Trans Biomed Eng, 55(11), 2675-2678.

do Nascimento, O. F., Nielsen, K. D., \& Voigt, M. (2005, January). Relationship between plantar-flexor torque generation and the magnitude of the movement-related potentials. Exp Brain Res, 160(2), 154-165.

do Nascimento, O. F., Nielsen, K. D., \& Voigt, M. (2006, May). Movement-related parameters modulate cortical activity during imaginary isometric plantar-flexions. Exp Brain Res, 171(1), 78-90.

Doyle, L. M. F., Yarrow, K., \& Brown, P. (2005, August). Lateralization of event-related beta desynchronization in the eeg during pre-cued reaction time tasks. Clin Neurophysiol, 116 (8), 1879-1888. doi:10.1016/j.clinph.2005.03.017

Georgopoulos, A. P., Kalaska, J. F., Caminiti, R., \& Massey, J. T. (1982, November). On the relations between the direction of two-dimensional arm movements and cell discharge in primate motor cortex. J Neurosci, 2(11), 1527-1537.

Gómez, C. M., Marco, J., \& Grau, C. (2003, September). Preparatory visuo-motor cortical network of the contingent negative variation estimated by current density. Neuroimage, 20(1), 216-224.2

Graimann, B., \& Pfurtscheller, G. (2006). Quantification and visualization of event-related changes in oscillatory brain activity in the time-frequency domain. Prog Brain Res, 159, 79-97.

Guo, F., Hong, B., Gao, X., \& Gao, S. (2008, December). A brain-computer interface using motion-onset visual evoked potential. J Neural Eng, 5(4), 477-485.

Gu, Y., do Nascimento, O. F., Lucas, M.-F., \& Farina, D. (2009, December). Identification of task parameters from movement related cortical potentials. Med Biol Eng Comput, 47(12), 1257-1264.

Hammon, P. S., Makeig, S., Poizner, H., Todorov, E., \& de Sa, V. R. (2008, January). Predicting reaching targets from human EEG. IEEE Signal Processing Magazine, 25(1), 69-77.

Hari, R. (2006). Action-perception connection and the cortical mu rhythm. Prog Brain Res, 159, $253-260$.

Hatsopoulos, N. G., \& Donoghue, J. P. (2009). The science of neural interface systems. Annu Rev Neurosci, 32, 249-266. doi:10.1146/annurev.neuro.051508.135241

Hink, R. F., Deecke, L., \& Kornhuber, H. H. (1983). Force uncertainty of voluntary movement and human movement-related potentials. Biol Psychol, 16(3-4), 197-210.

Hjorth, B. (1991, October). Principles for transformation of scalp EEG from potential field into source distribution. J Clin Neurophysiol, 8(4), 391-396.

Hlawatsch, F., \& Auger, F. (2008). Time-frequency analysis: concepts and methods. Digital signal and image processing series. ISTE.

Jahanshahi, M., Jenkins, I. H., Brown, R. G., Marsden, C. D., Passingham, R. E., \& Brooks, D. J. (1995, August). Self-initiated versus externally triggered movements. i. an investigation using measurement of regional cerebral blood flow with pet and movement-related potentials in normal and parkinson's disease subjects. Brain, 118 ( Pt 4), 913-933.

Jolliffe, I. (2002). Principal component analysis (2nd ed.). Springer.

Jordan, M., \& Wolpert, D. (1999). Computational motor control. In M. Gazzaniga (Ed.), The cognitive neuroscience (pp. 601-620). Cambridge, MA: MIT Press.

Koessler, L., Maillard, L., Benhadid, A., Vignal, J. P., Felblinger, J., Vespignani, H., \& Braun, M. (2009, May). Automated cortical projection of EEG sensors: anatomical correlation via the international 10-10 system. Neuroimage, 46(1), 64-72. doi:10.1016/j.neuroimage.2009.02.006

Leuthold, H., \& Jentzsch, I. (2009, May). Planning of rapid aiming movements and the contingent negative variation: are movement duration and extent specified independently? Psychophysiology, 46(3), 539-550.

Lindsay, K. A., \& Rosenberg, J. R. (2011, June). Identification of directed interactions in networks. Biol Cybern, 104(6), 385-396. doi:10.1007/s00422-011-0437-7 
MacKay, W. A., \& Bonnet, M. (1990, July). CNV, stretch reflex and reaction time correlates of preparation for movement direction and force. Electroencephalogr Clin Neurophysiol, 76(1), 47-62.

Mani, S., Mutha, P. K., Przybyla, A., Haaland, K. Y., Good, D. C., \& Sainburg, R. L. (2013, April). Contralesional motor deficits after unilateral stroke reflect hemisphere-specific control mechanisms. Brain, 136(Pt 4), 1288-1303. doi:10.1093/brain/aws283

Masakado, Y., \& Nielsen, J. B. (2008, March). Task-and phase-related changes in cortico-muscular coherence. Keio J Med, 57(1), 50-56.

McFarland, D. J., Krusienski, D. J., \& Wolpaw, J. R. (2006). Brain-computer interface signal processing at the wadsworth-center: mu and sensorimotor beta rhythms. Prog Brain Res, 159, 411-419.

Misiti, M., Misiti, Y., Oppenheim, G., \& Poggi, J.-M. (2007). Wavelets and their applications (M. Misiti, Y. Misiti, G. Oppenheim \& J.-M. Poggi, Eds.). London: ISTE.

Muthukumaraswamy, S. D. (2013). High-frequency brain activity and muscle artifacts in meg/eeg: a review and recommendations. Front Hum Neurosci, 7, 138. doi:10.3389/fnhum.2013.00138

Nasseroleslami, B., Lakany, H., \& Conway, B. A. (2011). Event-related (de-)synchronisation in arm isometric exertions: a wavelet analysis. In Proc. ieee symp. computational intelligence, cognitive algorithms, mind, and brain (ccmb) (pp. 1-7). doi:10.1109/CCMB.2011.5952112

Nasseroleslami, B. (2013). EEG signatures and directional information in planning and execution of arm isometric exertions (Doctoral dissertation, Department of Biomedical Engineering, University of Strathclyde, Glasgow, Scotland, UK).

Neuper, C., Müller-Putz, G. R., Scherer, R., \& Pfurtscheller, G. (2006). Motor imagery and EEG-based control of spelling devices and neuroprostheses. Prog Brain Res, 159, 393-409.

Oda, S., Shibata, M., \& Moritani, T. (1996, December). Force-dependent changes in movement-related cortical potentials. J Electromyogr Kinesiol, 6(4), 247-252.

Okamoto, M., Dan, H., Sakamoto, K., Takeo, K., Shimizu, K., Kohno, S., ... Dan, I. (2004, January). Threedimensional probabilistic anatomical cranio-cerebral correlation via the international 10-20 system oriented for transcranial functional brain mapping. Neuroimage, 21(1), 99-111.

Pelli, D. G. (1997). The videotoolbox software for visual psychophysics: transforming numbers into movies. Spat Vis, 10(4), 437-442.

Pfurtscheller, G., \& da Silva, F. H. L. (1999, November). Event-related EEG/MEG synchronization and desynchronization: basic principles. Clin Neurophysiol, 110(11), 1842-1857.

Pfurtscheller, G. (2006). The cortical activation model (CAM). Prog Brain Res, 159, 19-27.

Pfurtscheller, G., Solis-Escalante, T., Barry, R. J., Klobassa, D. S., Neuper, C., \& Müller-Putz, G. R. (2013). Brisk heart rate and EEG changes during execution and withholding of cue-paced foot motor imagery. Front Hum Neurosci, 7, 379. doi:10.3389/fnhum.2013.00379

Pineda, J. A. (2005, December). The functional significance of mu rhythms: translating "seeing" and "hearing" into "doing". Brain Res Brain Res Rev, 50(1), 57-68. doi:10.1016/j.brainresrev.2005.04.005

Reis, J., Robertson, E., Krakauer, J. W., Rothwell, J., Marshall, L., Gerloff, C., ... Cohen, L. G. (2008, October). Consensus: "can tDCS and TMS enhance motor learning and memory formation?" Brain Stimulat, 1(4), 363-369.

Romero, D. H., Lacourse, M. G., Lawrence, K. E., Schandler, S., \& Cohen, M. J. (2000, December). Eventrelated potentials as a function of movement parameter variations during motor imagery and isometric action. Behav Brain Res, 117(1-2), 83-96.

Salenius, S., \& Hari, R. (2003, December). Synchronous cortical oscillatory activity during motor action. Curr Opin Neurobiol, 13(6), 678-684.

Sanei, S. \& Chambers, J. A. (2007). EEG signal processing. Wiley-Interscience.

Schaal, S., Sternad, D., Osu, R., \& Kawato, M. (2004, October). Rhythmic arm movement is not discrete. Nat Neurosci, 7(10), 1136-1143. doi:10.1038/nn1322 
Schaefer, S. Y., Haaland, K. Y., \& Sainburg, R. L. (2009, November). Hemispheric specialization and functional impact of ipsilesional deficits in movement coordination and accuracy. Neuropsychologia, 47(13), 2953-2966. doi:10 . 1016 / j .neuropsychologia.2009.06.025

Schalk, G., Kubánek, J., Miller, K. J., Anderson, N. R., Leuthardt, E. C., Ojemann, J. G., ... Wolpaw, J. R. (2007, September). Decoding two-dimensional movement trajectories using electrocorticographic signals in humans. J Neural Eng, 4(3), 264-275.

Schoffelen, J.-M., Oostenveld, R., \& Fries, P. (2008, June). Imaging the human motor system's beta-band synchronization during isometric contraction. Neuroimage, 41(2), 437-447.

Sergio, L. E., Hamel-Paquet, C., \& Kalaska, J. F. (2005, October). Motor cortex neural correlates of output kinematics and kinetics during isometric-force and arm-reaching tasks. J Neurophysiol, 94(4), 2353-78. 0022-3077 (Print) Journal Article.

Sergio, L. E., \& Kalaska, J. F. (2003, January). Systematic changes in motor cortex cell activity with arm posture during directional isometric force generation. J Neurophysiol, 89(1), 212-28. 0022-3077 (Print) Journal Article.

Shadmehr, R., \& Wise, S. P. (2005). The computational neurobiology of reaching and pointing : a foundation for motor learning. Computational neuroscience. Reza Shadmehr and Steven P. Wise. ill. ; 26 cm. A Bradford book. Cambridge, MA: MIT Press.

Shalit, U., Zinger, N., Joshua, M., \& Prut, Y. (2012, August). Descending systems translate transient cortical commands into a sustained muscle activation signal. Cereb Cortex, 22(8), 1904-1914. doi:10.1093/cercor/bhr267

Shibasaki, H., \& Hallett, M. (2006, November). What is the bereitschaftspotential? Clin Neurophysiol, 117(11), 2341-2356.

Shibata, M., Oda, S., \& Moritani, T. (1997, June). The relationships between movement-related cortical potentials and motor unit activity during muscle contraction. J Electromyogr Kinesiol, 7(2), 79-85.

Siemionow, V., Yue, G. H., Ranganathan, V. K., Liu, J. Z., \& Sahgal, V. (2000, August). Relationship between motor activity related cortical potential and voluntary muscle activation. Exp Brain Res, 133(3), 303-311.

Slobounov, S. M., \& Ray, W. J. (1998, December). Movement-related potentials with reference to isometric force output in discrete and repetitive tasks. Exp Brain Res, 123(4), 461-473.

Slobounov, S., Johnston, J., Chiang, H., \& Ray, W. (2002, July). Movement-related EEG potentials are force or end-effector dependent: evidence from a multi-finger experiment. Clin Neurophysiol, 113(7), 1125-1135.

Soteropoulos, D., Edgley, S., \& Baker, S. (2011, July). Ipsilateral corticospinal contributions to control of the forelimb in monkey. In Physiological society abstracts (pp. 81-82). The Physiological Society. Cambridge, UK.

Srinivasan, R., Winter, W. R., \& Nunez, P. L. (2006). Source analysis of EEG oscillations using high-resolution EEG and MEG. Prog Brain Res, 159, 29-42.

Tzagarakis, C., Ince, N. F., Leuthold, A. C., \& Pellizzer, G. (2010, August). Beta-band activity during motor planning reflects response uncertainty. J Neurosci, 30 (34), 11270-11277. doi:10.1523/JNEUROSCI.6026-09.2010

Ulrich, R., Leuthold, H., \& Sommer, W. (1998, November). Motor programming of response force and movement direction. Psychophysiology, 35(6), 721-728.

Valsan, G. (2007). Brain computer interface using detection of movement intent. (Doctoral dissertation, University of Starthclyde).Waldert, S., Pistohl, T., Braun, C., Ball, T., Aertsen, A., \& Mehring, C. (2009). A review on directional information in neural signals for brain-machine interfaces. J Physiol Paris, 103(35), 244-254.

Waldert, S., Pistohl, T., Braun, C., Ball, T., Aertsen, A., \& Mehring, C. (2009). A review on directional information in neural signals for brain-machine interfaces. J Physiol Paris, 103(3-5), 244-254.

Waldert, S., Preissl, H., Demandt, E., Braun, C., Birbaumer, N., Aertsen, A., \& Mehring, C. (2008, January). Hand movement direction decoded from MEG and EEG. J Neurosci, 28(4), 1000-1008. 
Wilke, J. T., \& Lansing, R. W. (1973, September). Variations in the motor potential with force exerted during voluntary arm movements in man. Electroencephalogr Clin Neurophysiol, 35(3), 259-265.

Wolpaw, J. R. (2007, March). Brain-computer interfaces as new brain output pathways. J Physiol, 579(Pt 3), 613-619.

Zhang, Y., Chen, Y., Bressler, S. L., \& Ding, M. (2008, September). Response preparation and inhibition: the role of the cortical sensorimotor beta rhythm. Neuroscience, 156 (1), 238-246. doi:10.1016/j.neuroscience.2008.06.061 


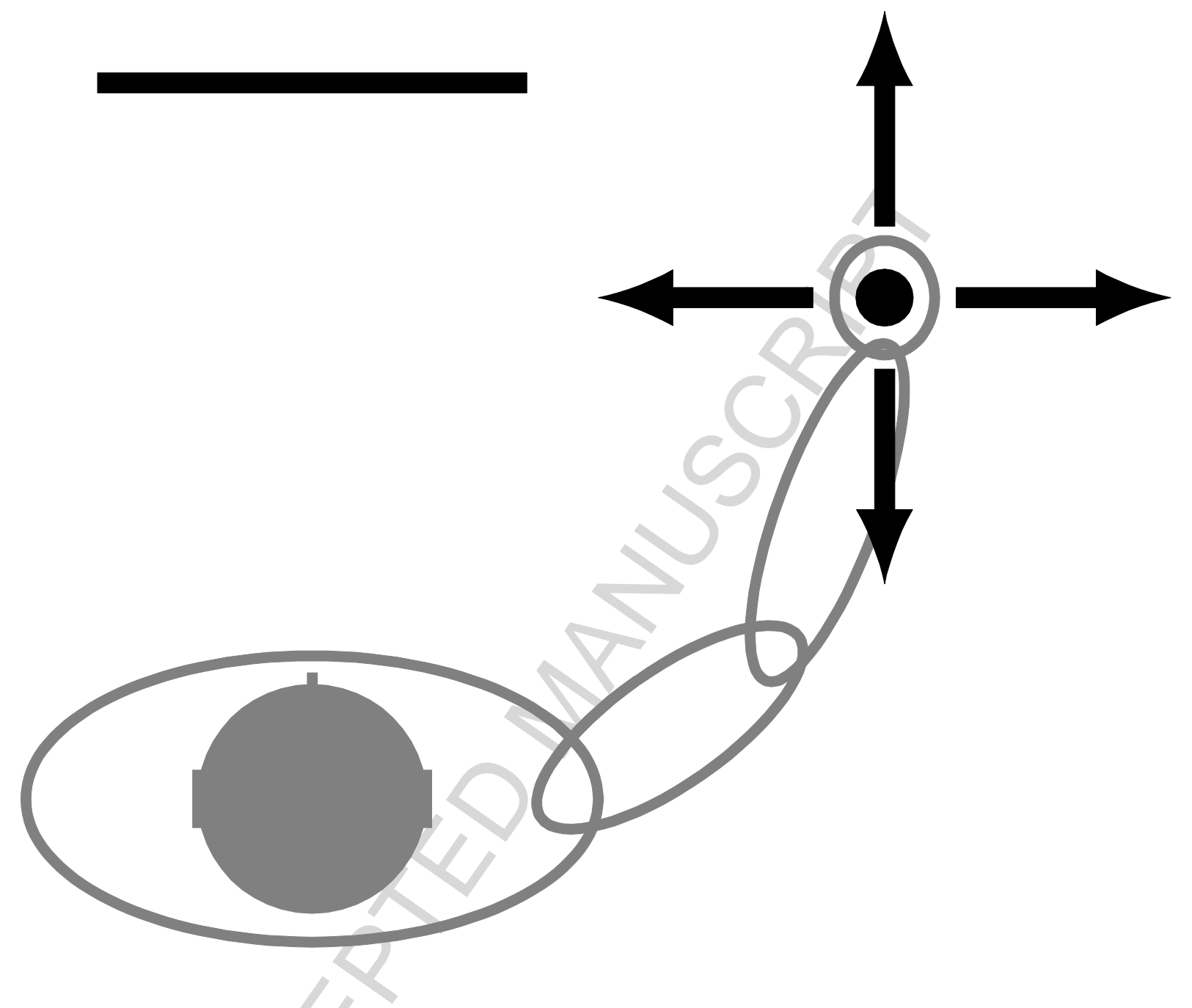

Figure 1a 


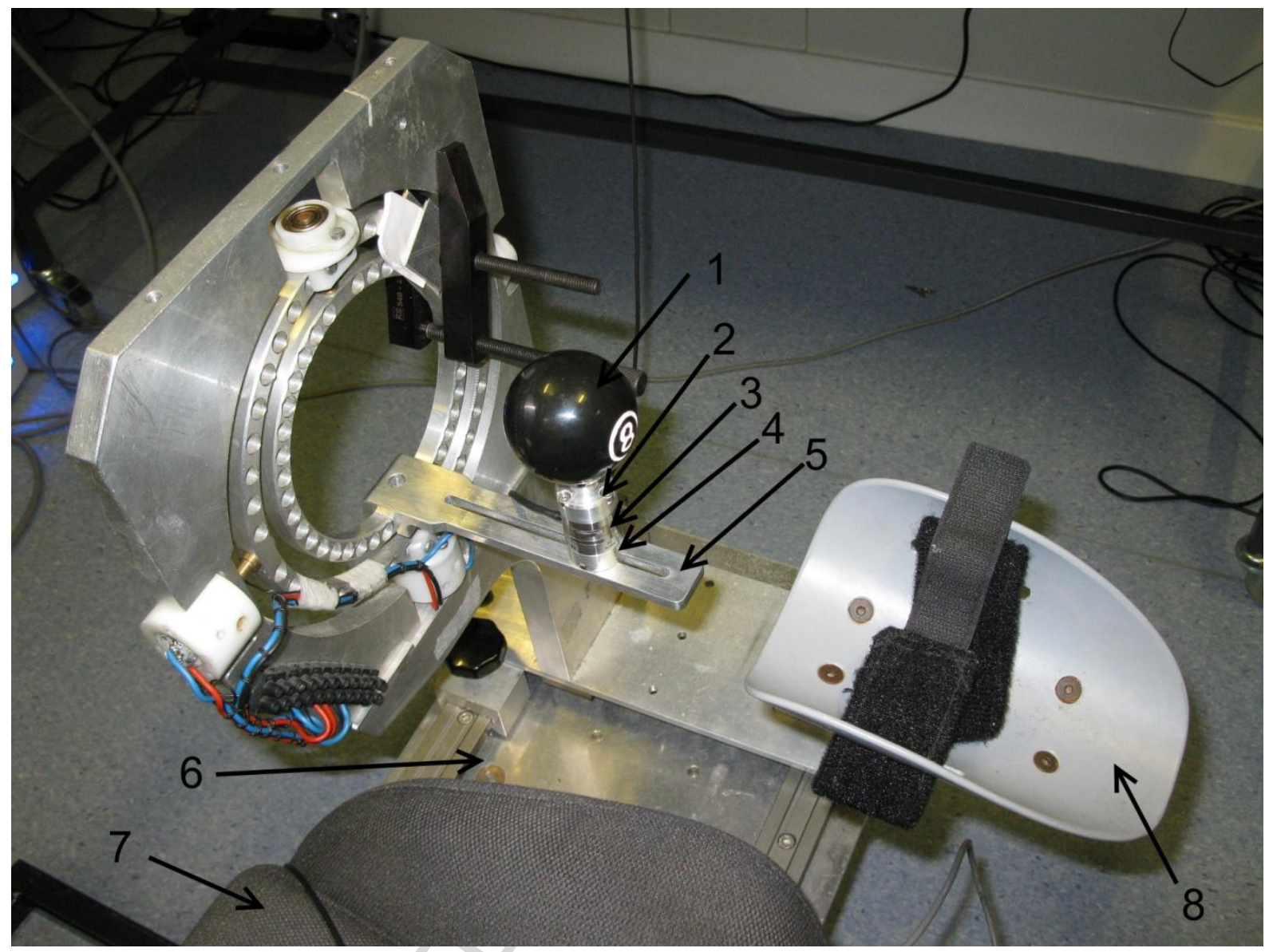

Figure 1b 
Page 23 of 33

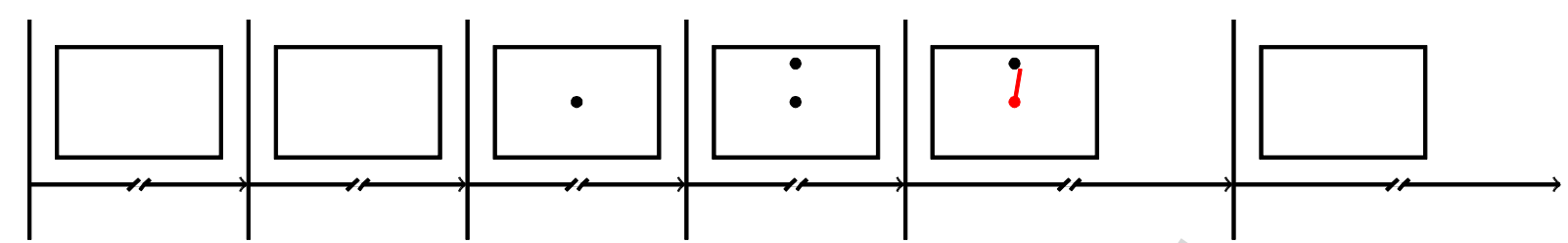

Figure 2 
ACCEPTED MANUSCRIPT

Page 24 of 33<smiles>CCC</smiles>
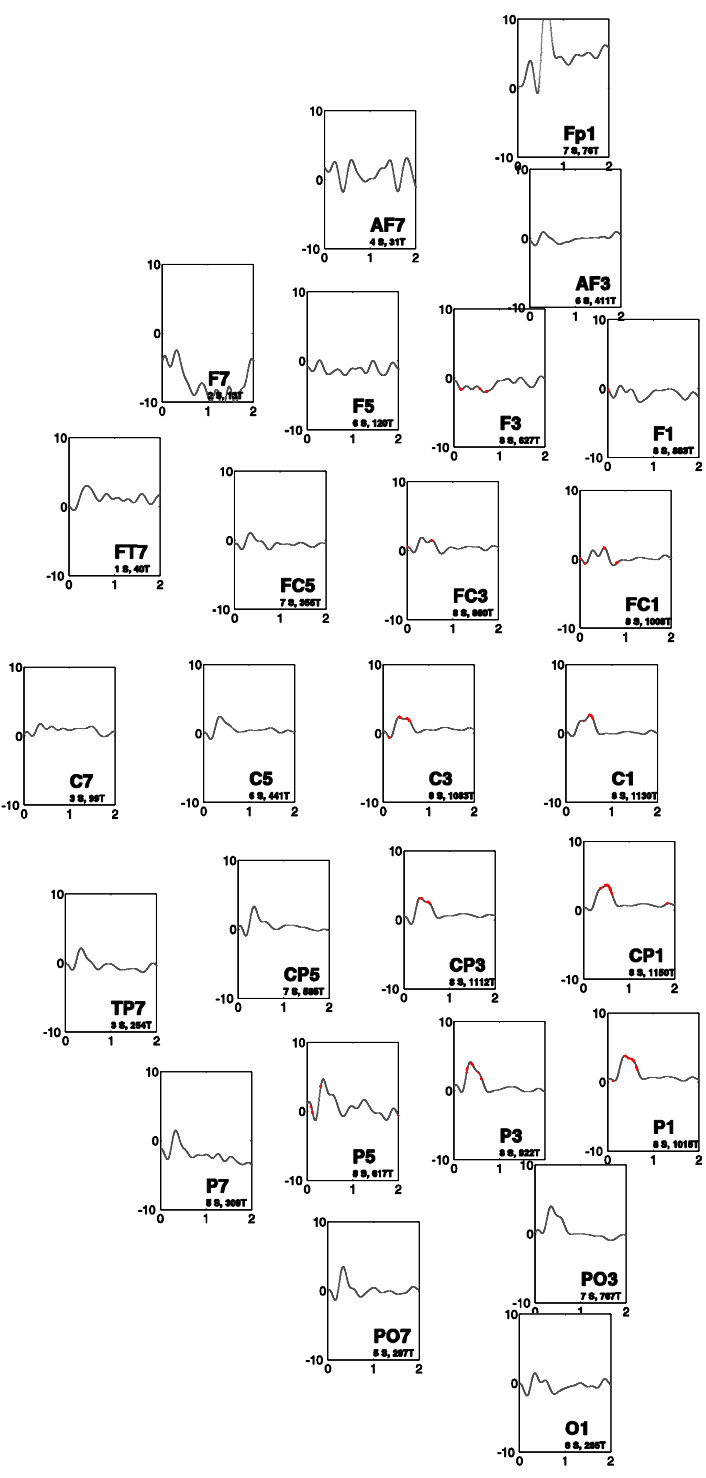
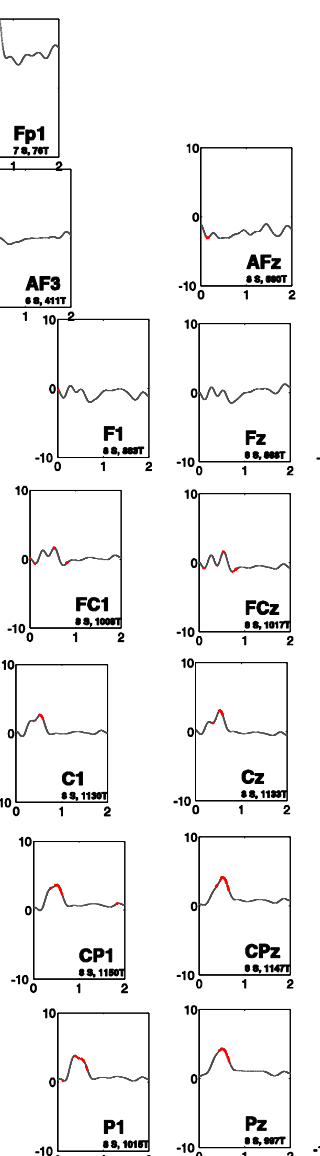

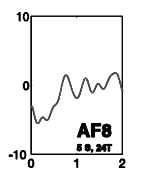

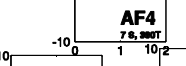
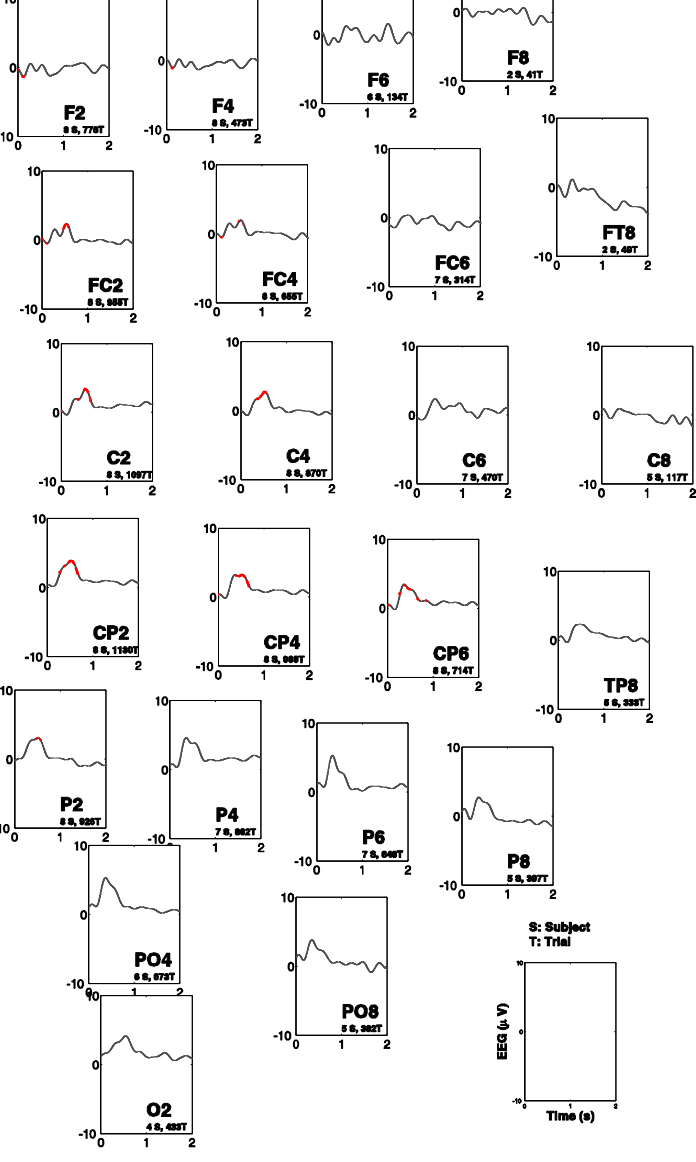

Figure 3 
ACCEPTED MANUSCRIPT

Page 25 of 33<smiles>CCC</smiles>
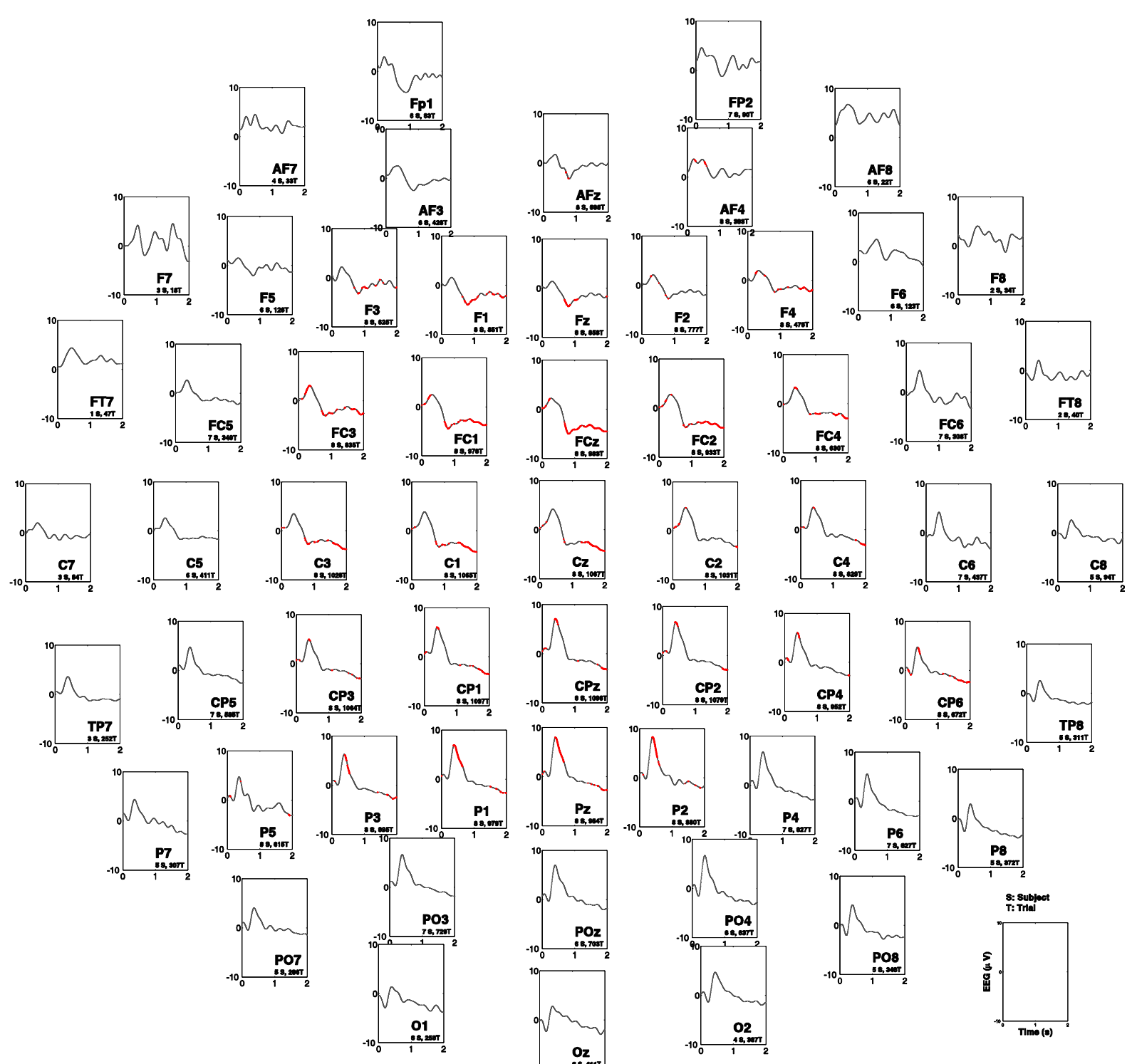

Figure 4 


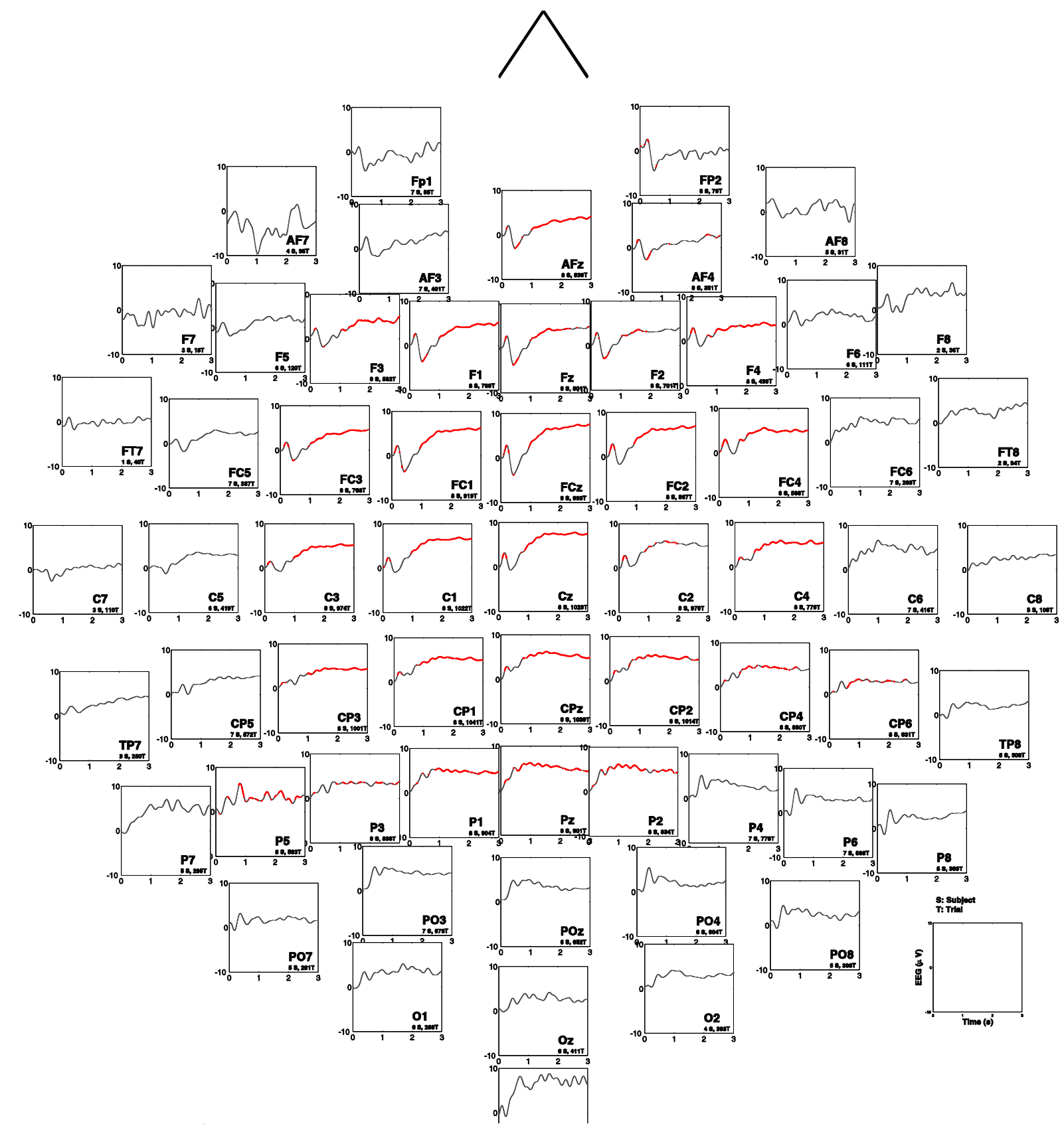

Figure 5 


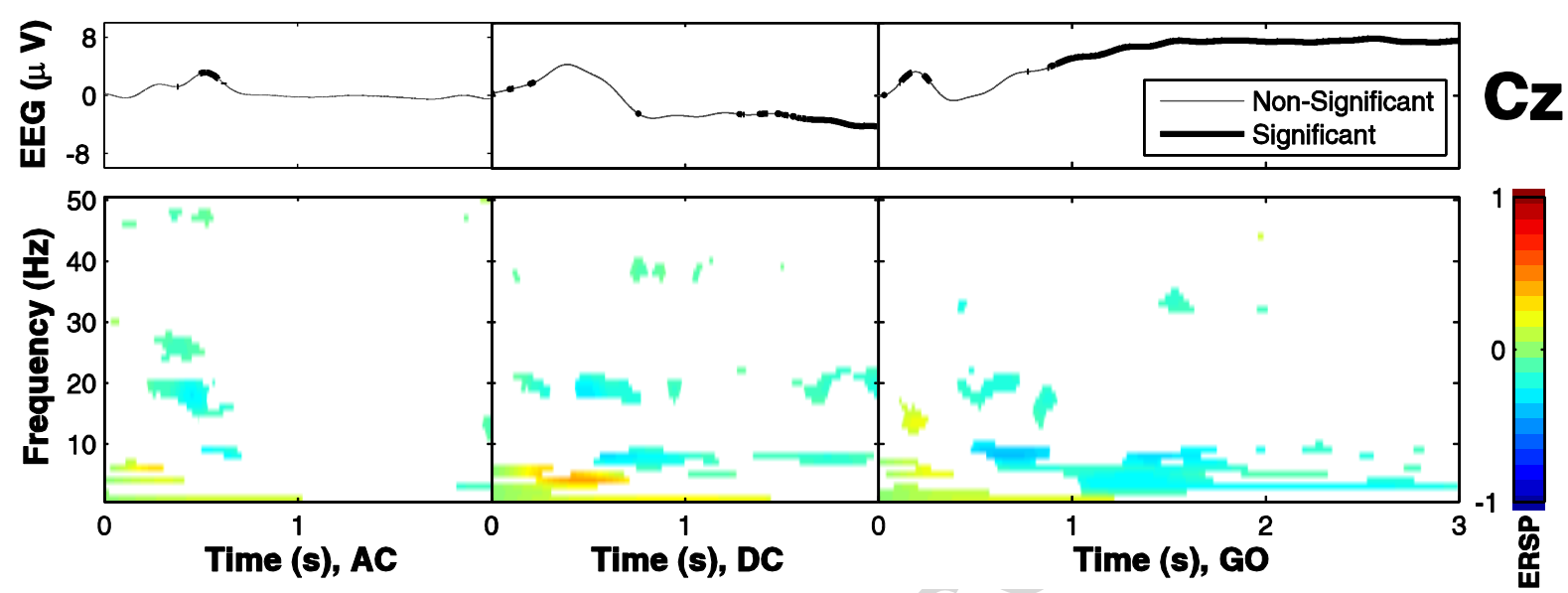

Figure 6 

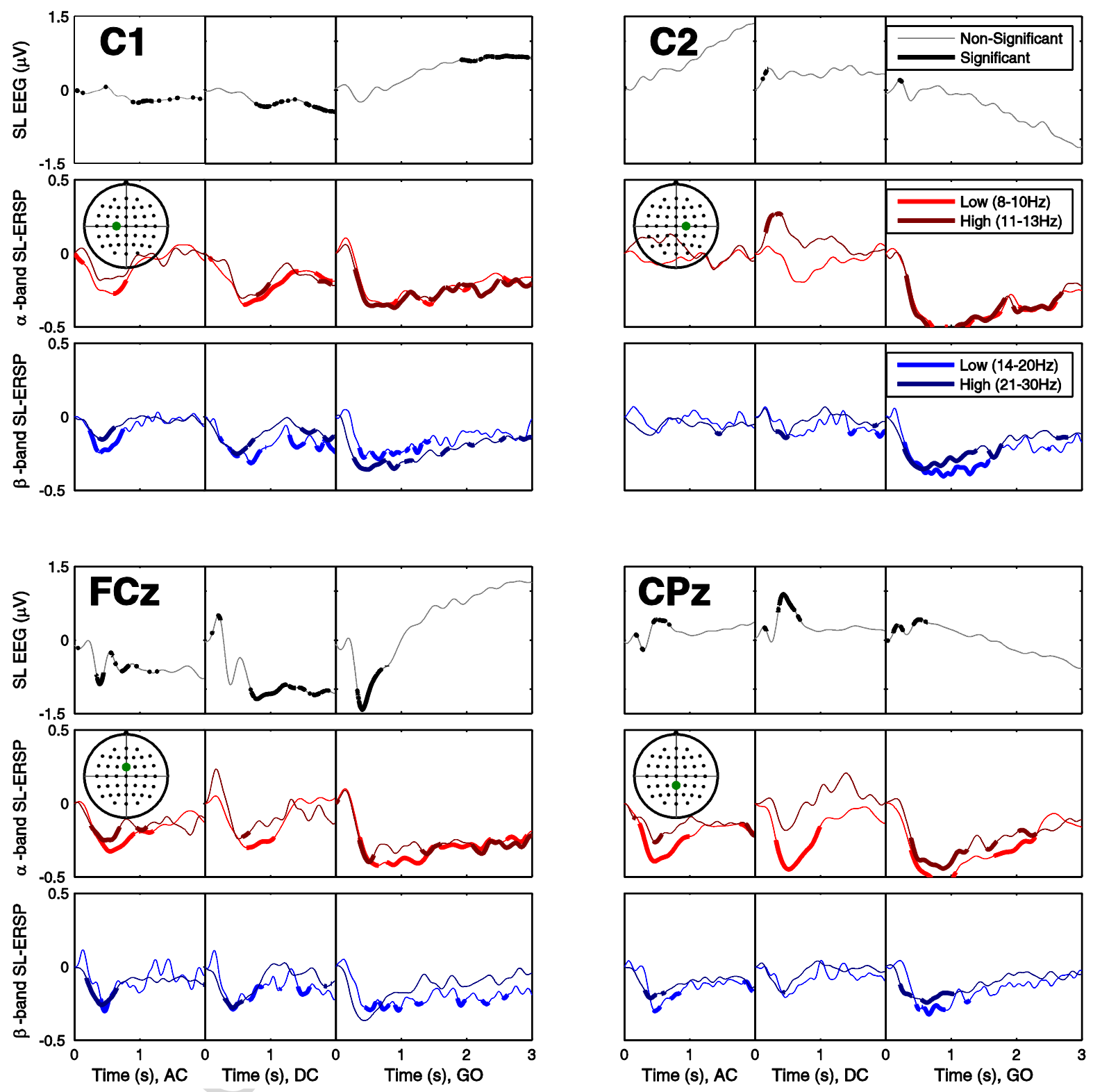

Figure 7 
Page 29 of 33

Table 1. Significant ear-lobe-referenced ERPs across all subjects.

\begin{tabular}{|c|c|c|c|c|c|c|}
\hline Ch & AC (Transient) & AC (Sustained) & DC (Transient) & DC (Sustained) & GO (Transient) & GO (Sustained) \\
\hline $\mathrm{Cz}$ & $\mathrm{P}(526,+3.085)$ & - & - & - & - & $\mathrm{S}(+7.460)$ \\
\hline $\mathrm{C} 1$ & - & - & - & - & - & $\mathrm{S}(+6.584)$ \\
\hline $\mathrm{C} 3$ & - & - & - & - & - & $\mathrm{S}(+5.132)$ \\
\hline $\mathrm{C} 4$ & - & - & - & - & - & $\mathrm{S}(+5.455)$ \\
\hline $\mathrm{FCz}$ & $\mathrm{N}(725,-1.298)$ & - & $\mathrm{N}(814,-4.967)$ & $\mathrm{S}(-3.829)$ & $\mathrm{N}(413,-3.817)$ & $S(+7.182)$ \\
\hline $\mathrm{FC} 1$ & $\mathrm{P}(526,+1.677)$ & - & $\mathrm{N}(812,-4.433)$ & $\mathrm{S}(-3.214)$ & $\mathrm{N}(415,-3.554)$ & $\mathrm{S}(+5.956)$ \\
\hline $\mathrm{FC} 2$ & $\mathrm{P}(528,+2.342)$ & - & - & $\mathrm{S}(-3.422)$ & - & $S(+6.577)$ \\
\hline FC3 & - & - & $\mathrm{N}(806,-3.069)$ & - & $\mathrm{N}(434,-2.272)$ & $\mathrm{S}(+4.322)$ \\
\hline FC4 & - & - & - & - & & $\mathrm{S}(+4.996)$ \\
\hline $\mathrm{CPz}$ & $\mathrm{P}(518,+4.168)$ & - & $\mathrm{P}(406,+7.117)$ & - & & $\mathrm{S}(+5.272)$ \\
\hline $\mathrm{CP} 1$ & $\mathrm{P}(509,+3.672)$ & - & $\mathrm{P}(396,+6.044)$ & . & & $\mathrm{S}(+5.210)$ \\
\hline $\mathrm{CP} 2$ & - & - & $\mathrm{P}(395,+6.819)$ & - & & $\mathrm{S}(+5.173)$ \\
\hline $\mathrm{CP} 3$ & - & - & - & - & - & $\mathrm{S}(+4.340)$ \\
\hline $\mathrm{Fz}$ & - & - & $\mathrm{N}(806,-3.639)$ & - & $\mathrm{N}(424,-3.674)$ & - \\
\hline F1 & - & - & $\mathrm{N}(806,-3.939)$ & . & $\mathrm{N}(421,-3.560)$ & $\mathrm{S}(+4.769)$ \\
\hline F2 & - & - & - & & $\mathrm{N}(440,-2.871)$ & - \\
\hline F3 & - & - & $\mathrm{N}(812,-3.177)$ & & $\mathrm{P}(174,+2.352)$ & $S(+4.139)$ \\
\hline F4 & - & - & - & & 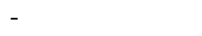 & $S(+3.749)$ \\
\hline $\mathrm{Pz}$ & $\mathrm{P}(510,+4.315)$ & - & $\mathrm{P}(402,+8.012)$ & & $\mathrm{P}(978,+6.272)$ & - \\
\hline P1 & - & - & $\mathrm{P}(390,+6.943)$ & & $\mathrm{P}(980,+5.538)$ & $\mathrm{S}(+4.623)$ \\
\hline P2 & - & - & $\mathrm{P}(400,+8.340)$ & & $\mathrm{P}(993,+6.219)$ & - \\
\hline $\mathrm{AFz}$ & - & - & - & - & - & $\mathrm{S}(+3.640)$ \\
\hline
\end{tabular}

Transient means the first $1.0 \mathrm{~s}$ after the cue where early activity is observed. Sustained, indicates the lasting activity that is sustained in the second second (for AC and DC) or third second (for GO) after the cue. P and N stand for positivity and negativity. Numbers in parentheses show the time delay in milliseconds and the value of the peak in average EEG $(\mu \mathrm{V})$; e.g. $\mathrm{P}(526,+3.085)$ shows a positive peak of $3.085 \mu \mathrm{V}, 526 \mathrm{~ms}$ after the relevant visual cue. $\mathrm{S}(-3.829)$ shows sustained average potential of -3.829 over the $1 \mathrm{~s}$ late period. The values are referenced to average signal values at the point of appearance of cues. 
Page 30 of 33

Table 2. Significant surface Laplacian ERPs across all subjects.

\begin{tabular}{lllllll}
\hline Ch & AC (Transient) & AC (Sustained) & DC (Transient) & DC (Sustained) & GO (Transient) & GO (Sustained) \\
\hline FCz & N(390,-0.900) & - & N(794,-1.205) & - & N $(406,-1.423)$ & - \\
FC1 & - & - & - & - & N(394,-0.929) & - \\
FC2 & - & - & N(781,-0.980) & - & - & - \\
CPz & P(500,+0.413) & - & P(436,+0.930) & - & $\mathrm{P}(515,+0.415)$ & - \\
CP1 & $\mathrm{P}(484,+0.476)$ & - & - & - & $\mathrm{P}(170,+0.217)$ & - \\
\hline
\end{tabular}

Transient means the first 1.0s after the cue where early activity is observed. Sustained, indicates the lasting activity that is sustained in the second second (for AC and DC) or third second (for GO) after the cue. P and $\mathrm{N}$ stand for positivity and negativity. Numbers in parentheses show the time delay in milliseconds and the value of the peak in average EEG $(\mu \mathrm{V})$; e.g. $\mathrm{P}(484,+0.476)$ shows a positive peak of $0.476 \mu \mathrm{V}, 488 \mathrm{~ms}$ after the relevant visual cue. The values are referenced to average signal values at the point of appearance of cues. 
Table 3. Significant ear-lobe-referenced ERD/ERS across all subjects for 5 selected electrodes.

\begin{tabular}{|c|c|c|c|c|c|c|}
\hline $\mathbf{C h}$ & AC (Transient) & AC (Sustained) & DC (Transient) & DC (Sustained) & GO (Transient) & GO (Sustained) \\
\hline $\mathrm{Cz}$ & $-[18-20]$ & & $\begin{array}{l}-[7-8] \\
-[18-20]\end{array}$ & $-[8]$ & $\begin{array}{l}-[8-9] \\
-[19]\end{array}$ & $-[3]$ \\
\hline $\mathrm{C} 3$ & $\begin{array}{l}-[16-20] \\
-[24]\end{array}$ & & $\begin{array}{l}-[7-9] \\
-[15-21]\end{array}$ & $+[1]$ & $\begin{array}{l}-[6] \\
-[8-10] \\
-[12] \\
-[18-20]\end{array}$ & $-[3]$ \\
\hline $\mathrm{C} 4$ & $\begin{array}{l}-[8-9] \\
-[17-18]\end{array}$ & $-[3]$ & $+[4]$ & $-[2]$ & $\begin{array}{l}-[6] \\
-[8-9] \\
-[18-21]\end{array}$ & $\begin{array}{l}-[3] \\
-[7-8]\end{array}$ \\
\hline $\mathrm{Fz}$ & $-[19]$ & $-[3]$ & $\begin{array}{l}-[7-8] \\
-[26-29]\end{array}$ & & & $-[11-15]$ \\
\hline $\mathrm{Pz}$ & $-[8]$ & & $-[8]$ & $+[1]$ & $\begin{array}{l}-[6-8] \\
-[10-13] \\
-[17-18]\end{array}$ & $\begin{array}{l}-[3-7] \\
-[9]\end{array}$ \\
\hline
\end{tabular}

+ shows ERS and - shows ERD. Numbers show frequency range in Hz. Transient means the first 1.0s after the cue where early activity is observed. Sustained, indicates the lasting activity that is sustained in the second second (for AC and DC) or third second (for GO) after the cue. 
Page 32 of 33

Table 4. Significant surface Laplacian ERD/ERS across all subjects for 5 selected electrodes.

\begin{tabular}{|c|c|c|c|c|c|c|}
\hline$\overline{C h}$ & AC (Transient) & $\overline{A C}$ (Sustained) & $\overline{D C}$ (Transient) & DC (Sustained) & GO (Transient) & GO (Sustained) \\
\hline $\mathrm{Cz}$ & $\begin{array}{l}-[2] \\
-[22]\end{array}$ & $-[2]$ & $\begin{array}{l}+[4-6] \\
-[7] \\
-[19-22]\end{array}$ & $\begin{array}{l}-[2] \\
-[22]\end{array}$ & $-[8-25]$ & $-[2-3]$ \\
\hline $\mathrm{C} 1$ & $\begin{array}{l}-[2] \\
-[9] \\
-[15-17]\end{array}$ & $-[2-3]$ & $\begin{array}{l}-[2] \\
+[5-6] \\
-[7-10] \\
-[14-25]\end{array}$ & $\begin{array}{l}-[2-3] \\
-[7-8]\end{array}$ & $\begin{array}{l}-[1-2] \\
+[6] \\
-[10-17] \\
-[22] \\
-[24-32] \\
-[38-39] \\
-[47-48]\end{array}$ & $\begin{array}{l}-[1-3] \\
-[10-12] \\
-[27-28]\end{array}$ \\
\hline $\mathrm{C} 2$ & $-[2]$ & & $\begin{array}{l}-[2] \\
-[7] \\
+[12]\end{array}$ & $-[2-3]$ & $\begin{array}{l}-[2] \\
-[8] \\
-[10-25] \\
-[32-40]\end{array}$ & $\begin{array}{l}-[5] \\
-[8-13] \\
-[20]\end{array}$ \\
\hline $\mathrm{FCz}$ & $\begin{array}{l}+[4] \\
+[6] \\
-[7-13] \\
-[22-29] \\
-[41]\end{array}$ & & $\begin{array}{l}+[3-5] \\
+[7] \\
-[8-9] \\
-[17] \\
-[21-23]\end{array}$ & $-[2]$ & $\begin{array}{l}-[2] \\
+[5] \\
-[7-9] \\
-[17-19] \\
-[28]\end{array}$ & $\begin{array}{l}-[2-3] \\
-[8] \\
-[11-14]\end{array}$ \\
\hline $\mathrm{CPz}$ & $\begin{array}{l}-[2-10] \\
-[17-23] \\
-[46]\end{array}$ & $\begin{array}{l}-[2-6] \\
-[8]\end{array}$ & $\begin{array}{l}-[2-3] \\
+[4] \\
-[6-10]\end{array}$ & $-[2-3]$ & $\begin{array}{l}-[2] \\
+[5] \\
-[6] \\
-[9-13] \\
-[17-23] \\
-[41-43]\end{array}$ & $\begin{array}{l}-[2-4] \\
-[6]\end{array}$ \\
\hline
\end{tabular}

+ shows ERS and - shows ERD. Numbers show frequency range in Hz. Transient means the first 1.0s after the cue where early activity is observed. Sustained, indicates the lasting activity that is sustained in the second second (for AC and DC) or third second (for GO) after the cue. 


\section{Highlights:}

Preparation, planning and execution of isometric motor tasks cause ERPs and ERDs. ERPs are negative in frontal and positive in parietal areas from superficial sources. ERD/ERSs are primarily in $\mu$ and $\beta$ bands, from deep and superficial brain sources. ERPs and ERDs are similar to those in movements and do not depend on arm coordinates. ERPs are comparable to invasive recordings in primates during movement. 


\section{Supplementary Figures:}

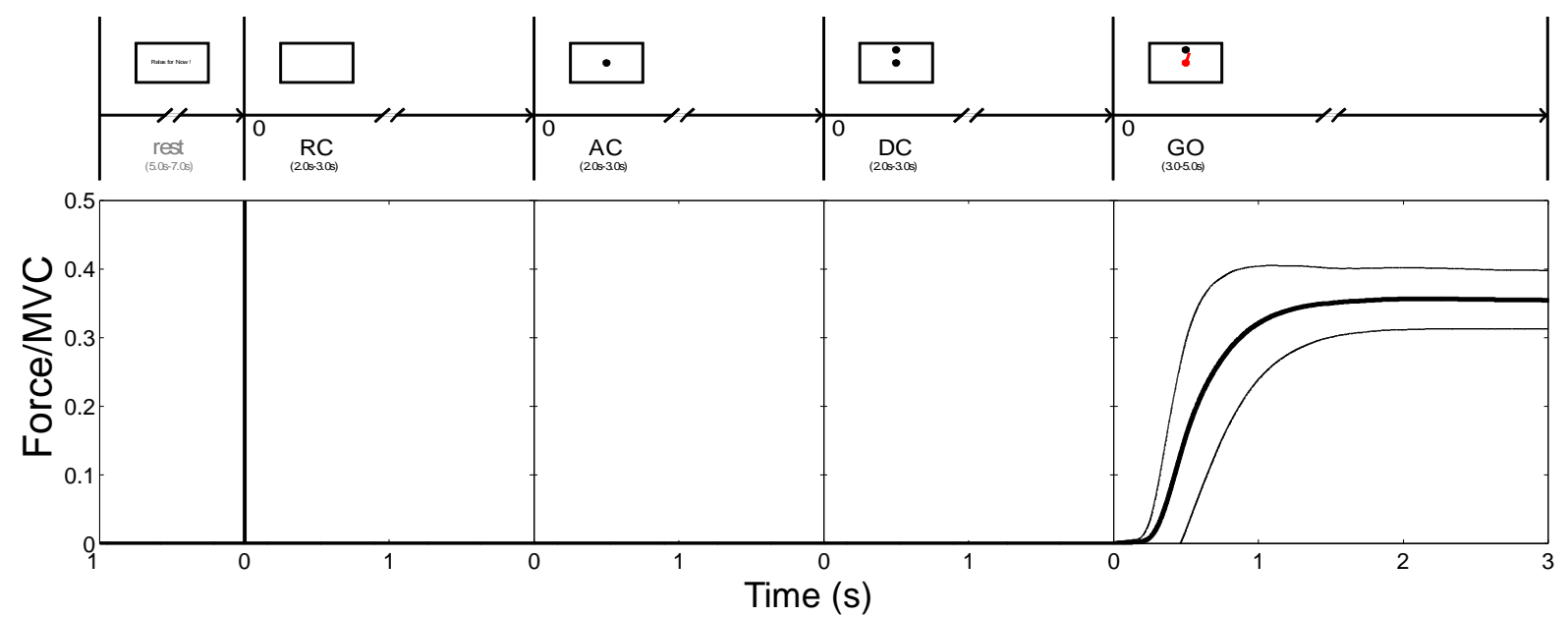

Figure S1. Average exerted force during the experiment. The thick line shows the average force across all trials and all subjects and thin boundary lines show the standard deviation. Different stages of the experiment are explained in Figure 2. 


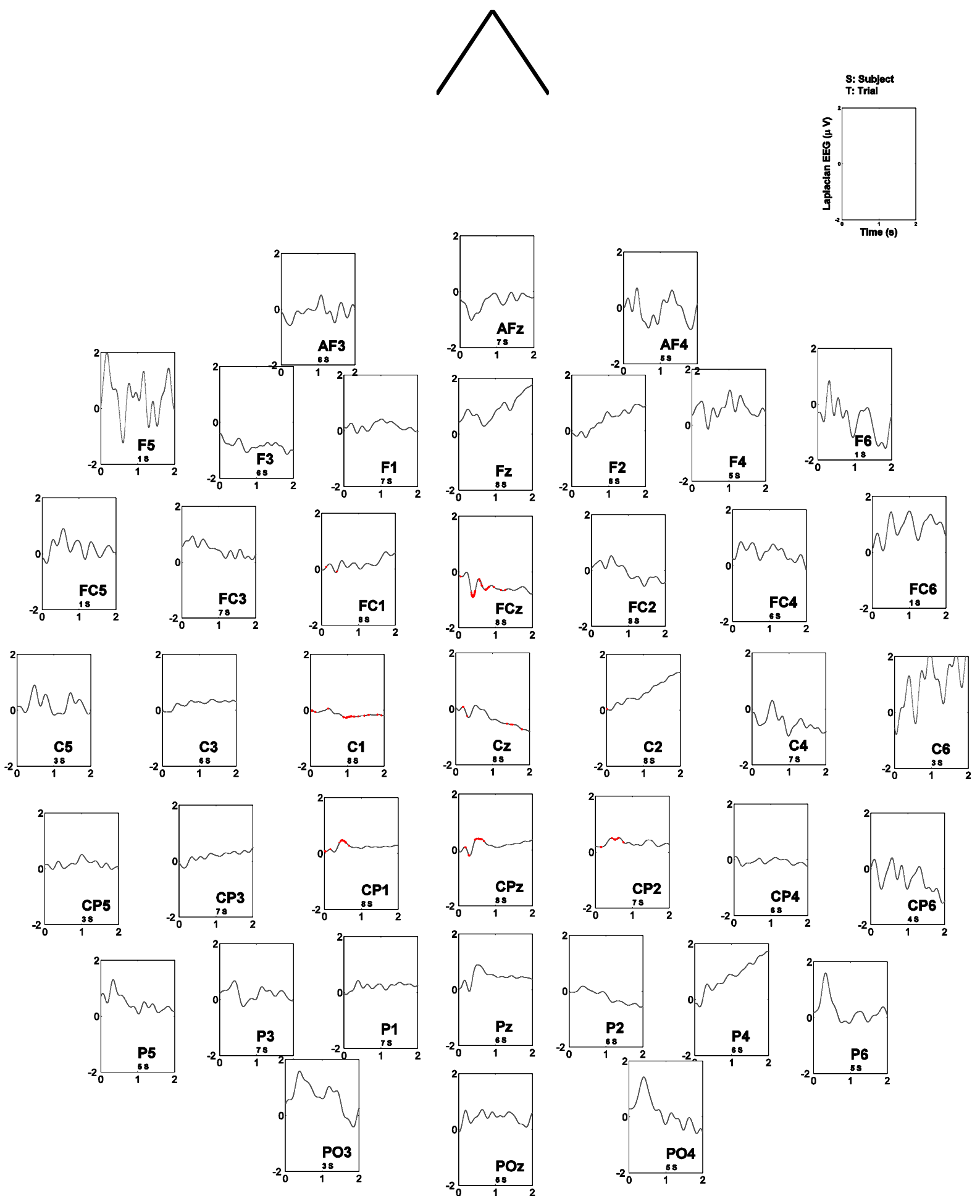

Figure S2. Surface Laplacian ERP $(\mu \mathrm{V})$ across scalp, averaged across 8 subjects during preparation (AC) stage. Thick lines show significant ERP at $\alpha=0.05$ after correction for multiple comparisons. 


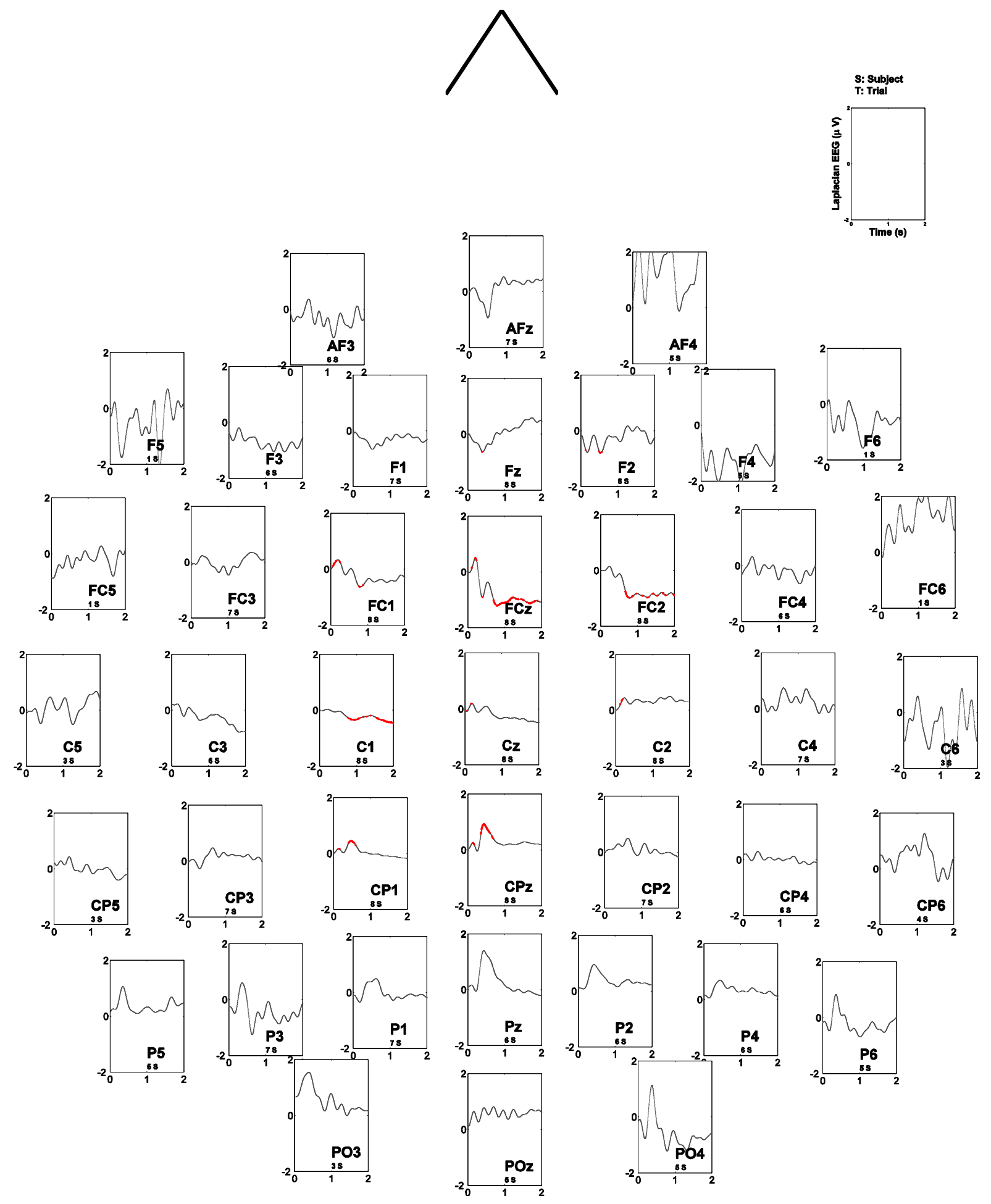

Figure S3. Surface Laplacian ERP $(\mu \mathrm{V})$ across scalp, averaged across 8 subjects during planning (DC) stage.

Thick lines show significant ERP at $\alpha=0.05$ after correction for multiple comparisons. 


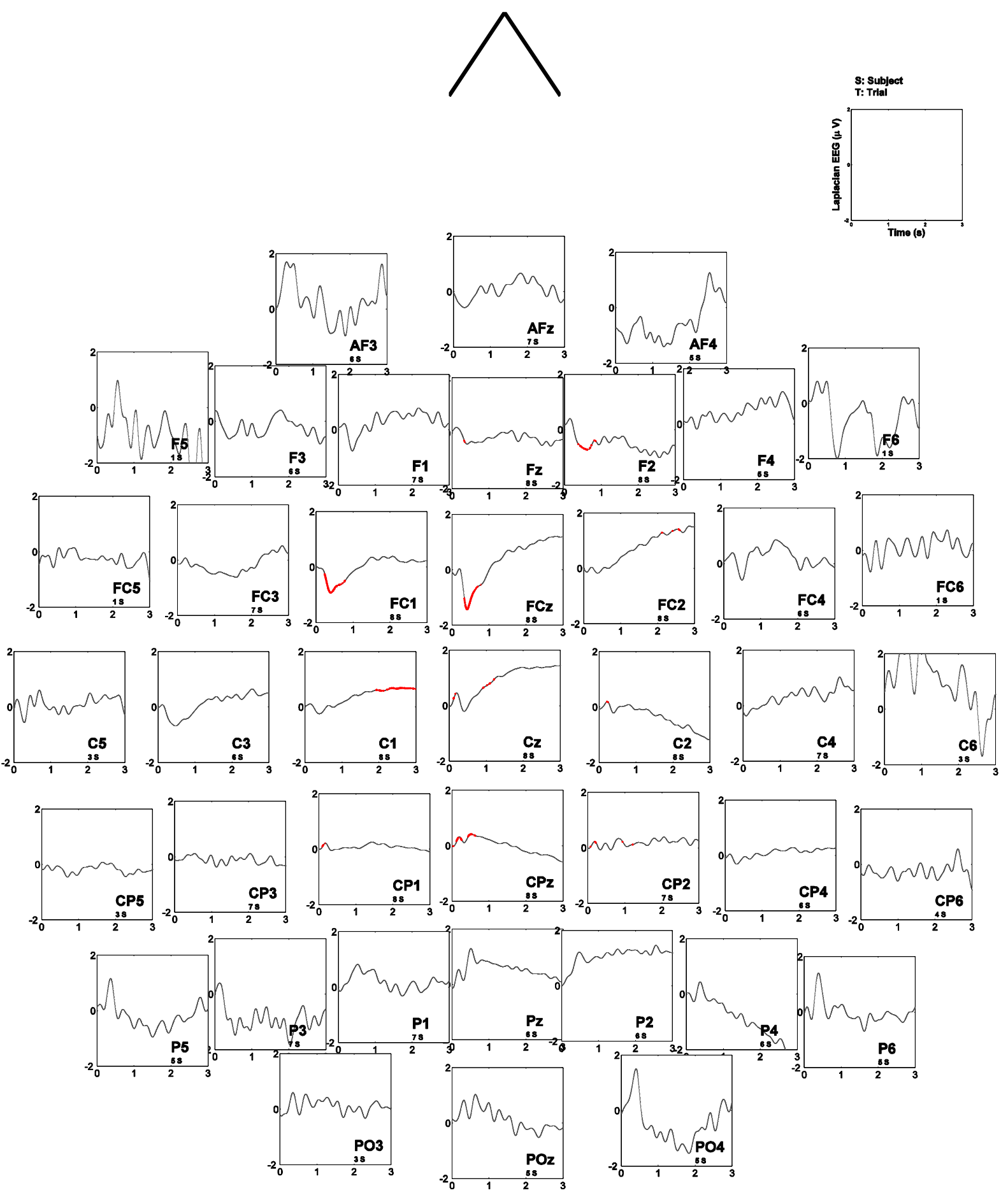

Figure S4. Surface Laplacian ERP $(\mu \mathrm{V})$ across scalp, averaged across 8 subjects during execution (GO) stage. Thick lines show significant ERP at $\alpha=0.05$ after correction for multiple comparisons. 


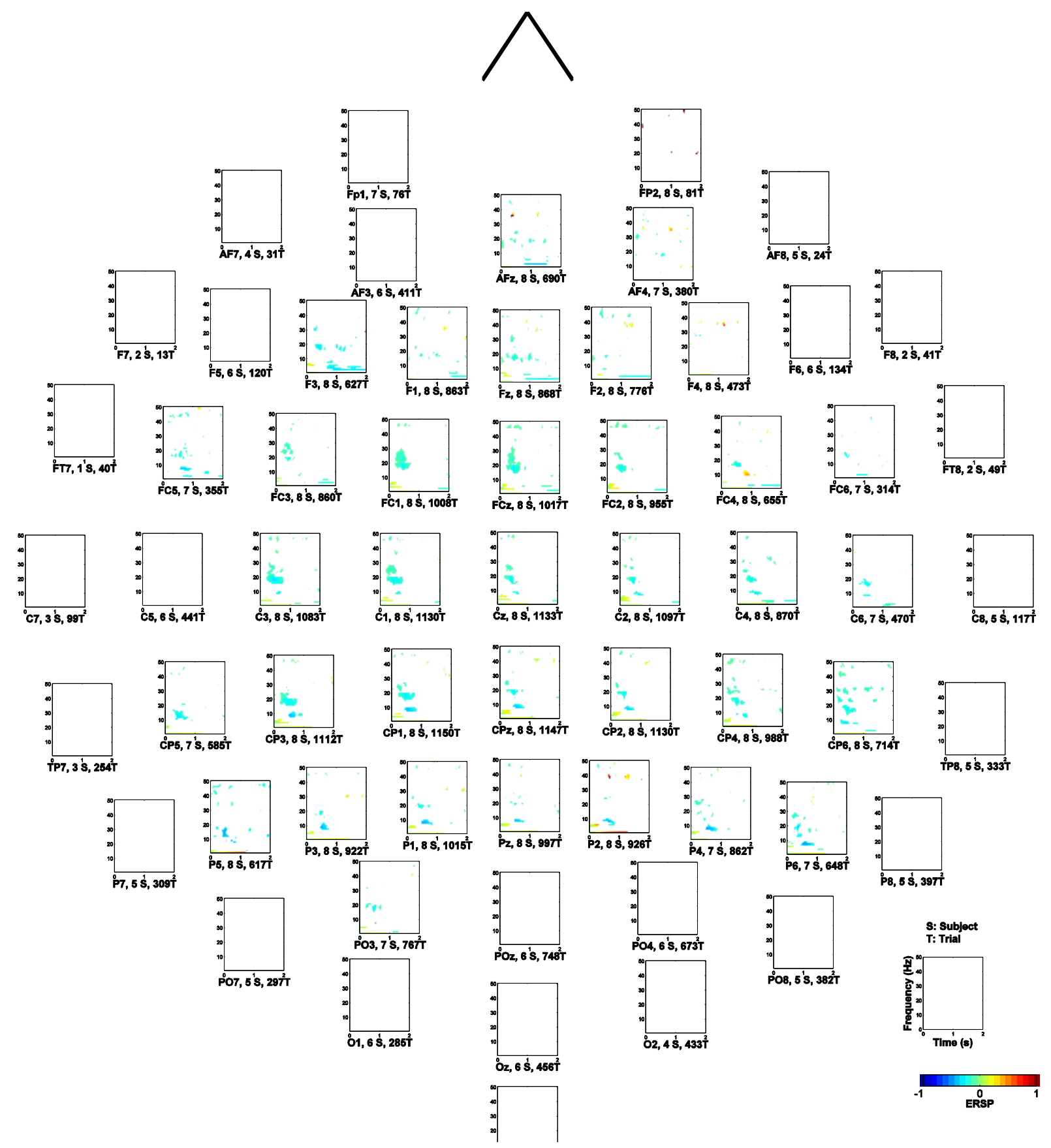

Figure S5. Event-Related Spectral Perturbation (ERSP) of ear-lobe-referenced EEG (ERD/ERS ratio) across scalp electrodes, averaged across 8 subjects during preparation (AC) stage. For each electrode position the significant normalized continuous wavelet scalograms are plotted at $\alpha=0.05$ after correction for multiple comparisons. 


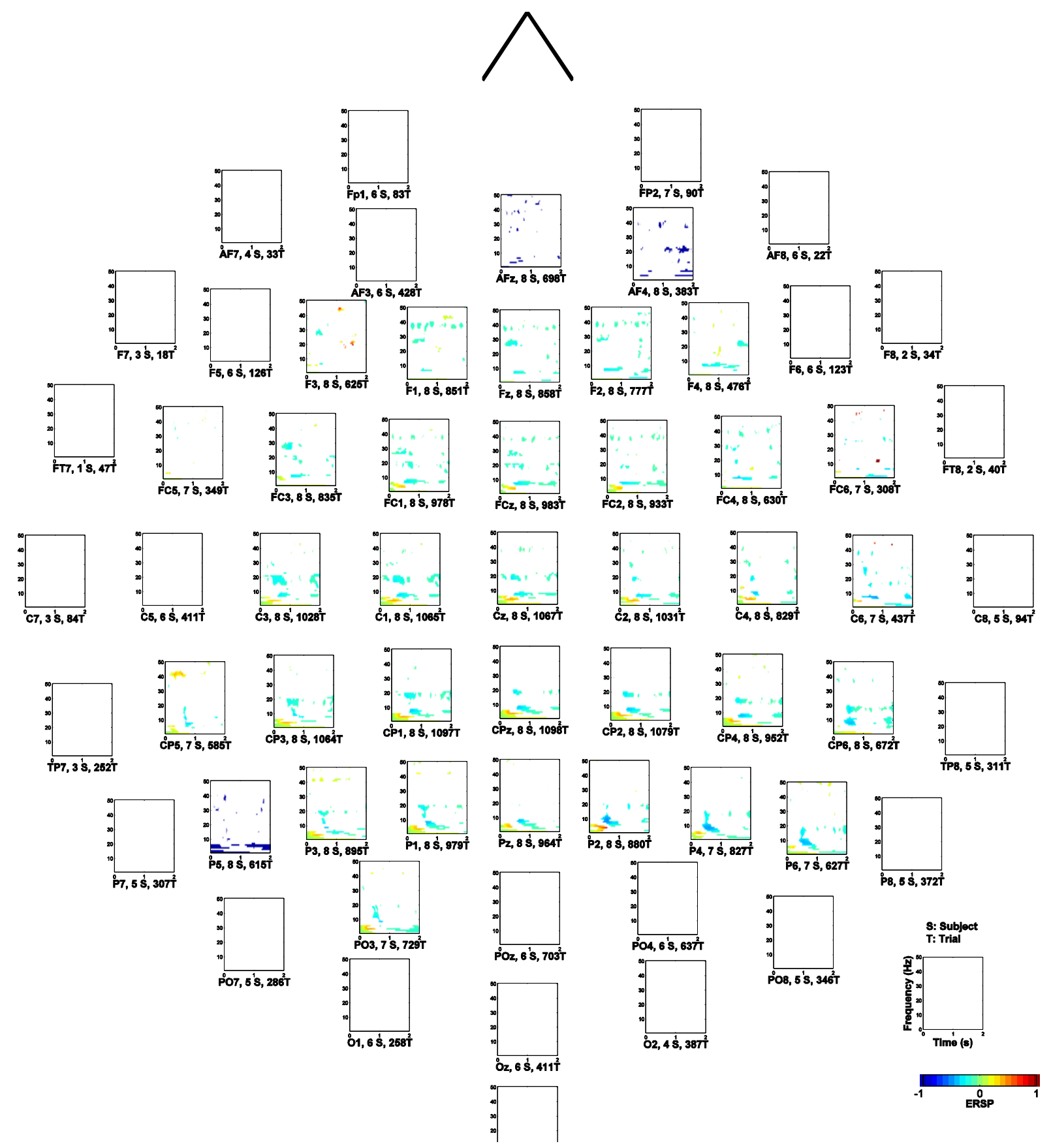

Figure S6. Event-Related Spectral Perturbation (ERSP) of ear-lobe-referenced EEG (ERD/ERS ratio) across scalp electrodes, averaged across 8 subjects during planning (DC) stage. For each electrode position the significant normalized continuous wavelet scalograms are plotted at $\alpha=0.05$ after correction for multiple comparisons. 


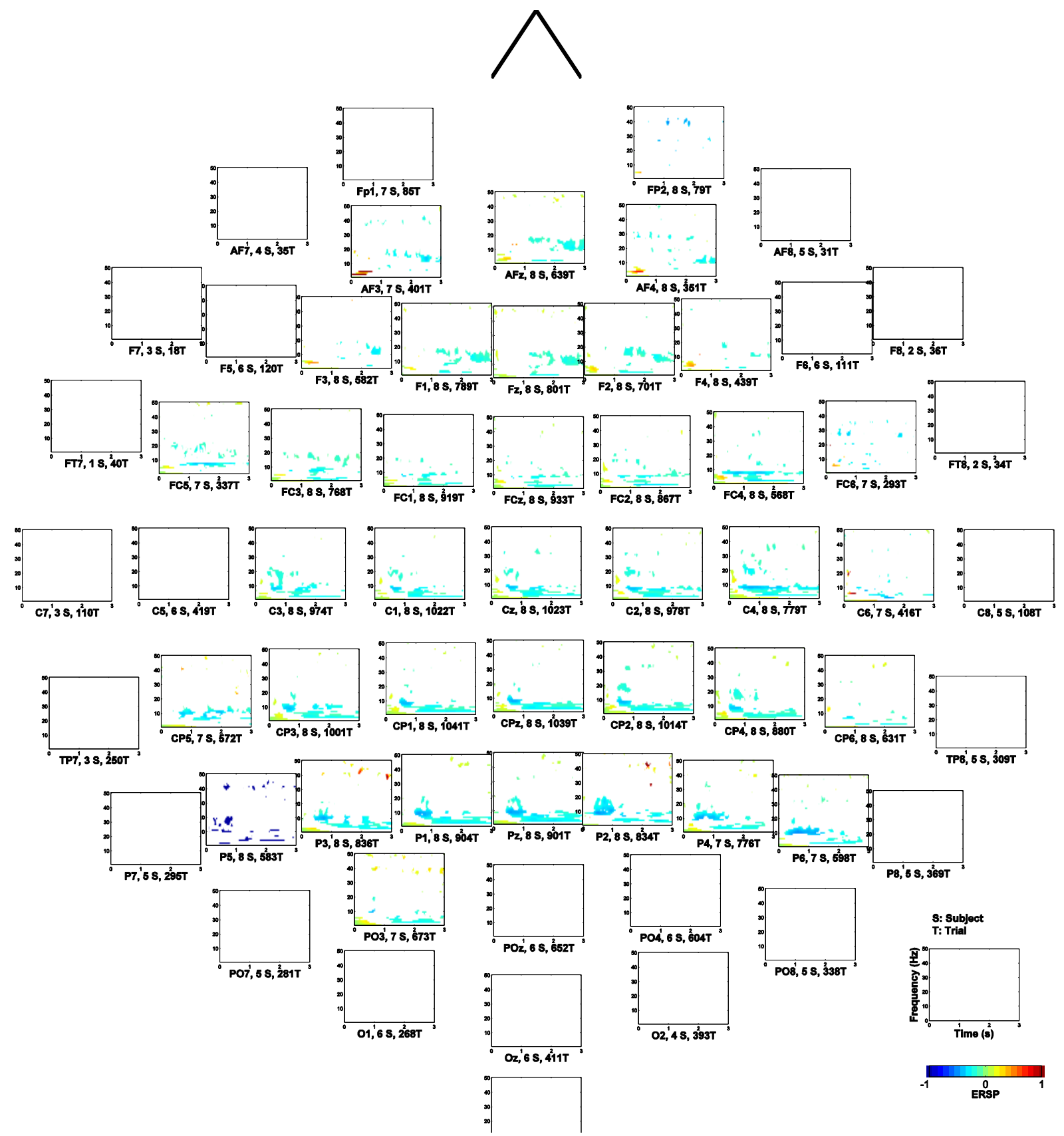

Figure S7. Event-Related Spectral Perturbation (ERSP) of ear-lobe-referenced EEG (ERD/ERS ratio) across scalp electrodes, averaged across 8 subjects during execution (GO) stage. For each electrode position the significant normalized continuous wavelet scalograms are plotted at $\alpha=0.05$ after correction for multiple comparisons. 


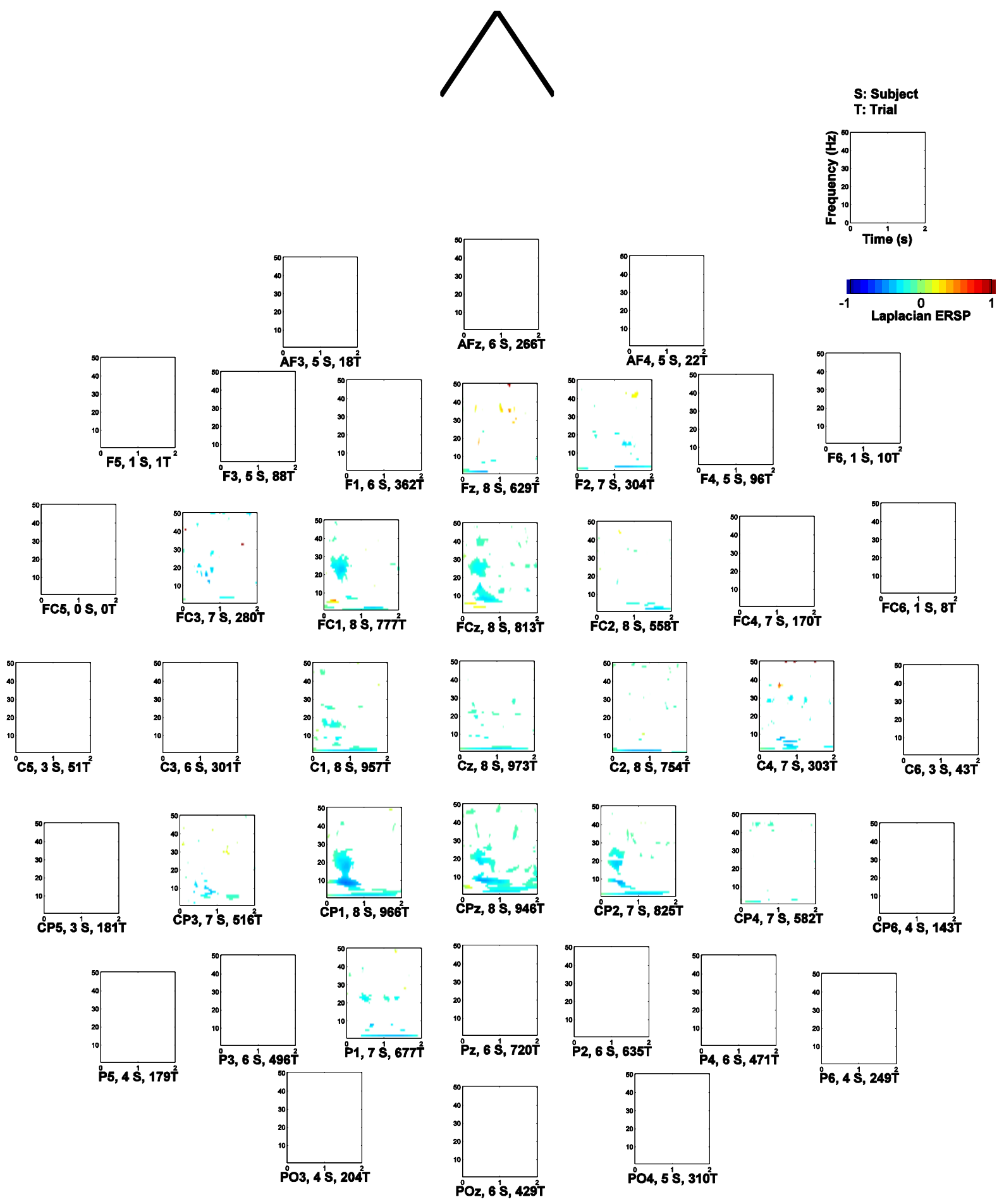

Figure S8. Event-Related Spectral Perturbation (ERSP) of surface Laplacian EEG (ERD/ERS ratio) across scalp electrodes, averaged across 8 subjects during preparation (AC) stage. For each electrode position the significant normalized continuous wavelet scalograms are plotted at $\alpha=0.05$ after correction for multiple comparisons. 


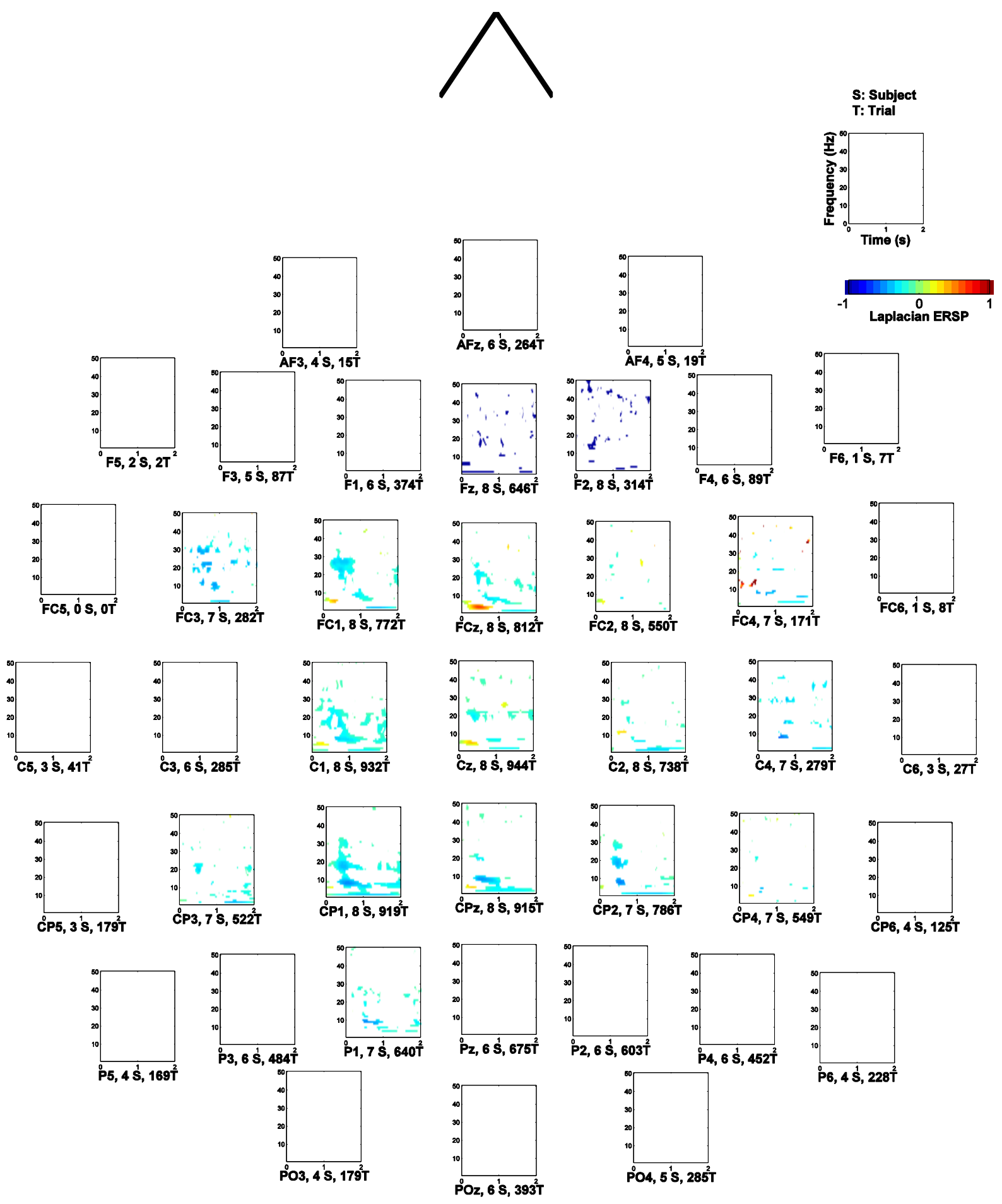

Figure S9. Event-Related Spectral Perturbation (ERSP) of surface Laplacian EEG (ERD/ERS ratio) across scalp electrodes, averaged across 8 subjects during planning (DC) stage. For each electrode position the significant normalized continuous wavelet scalograms are plotted at $\alpha=0.05$ after correction for multiple comparisons. 


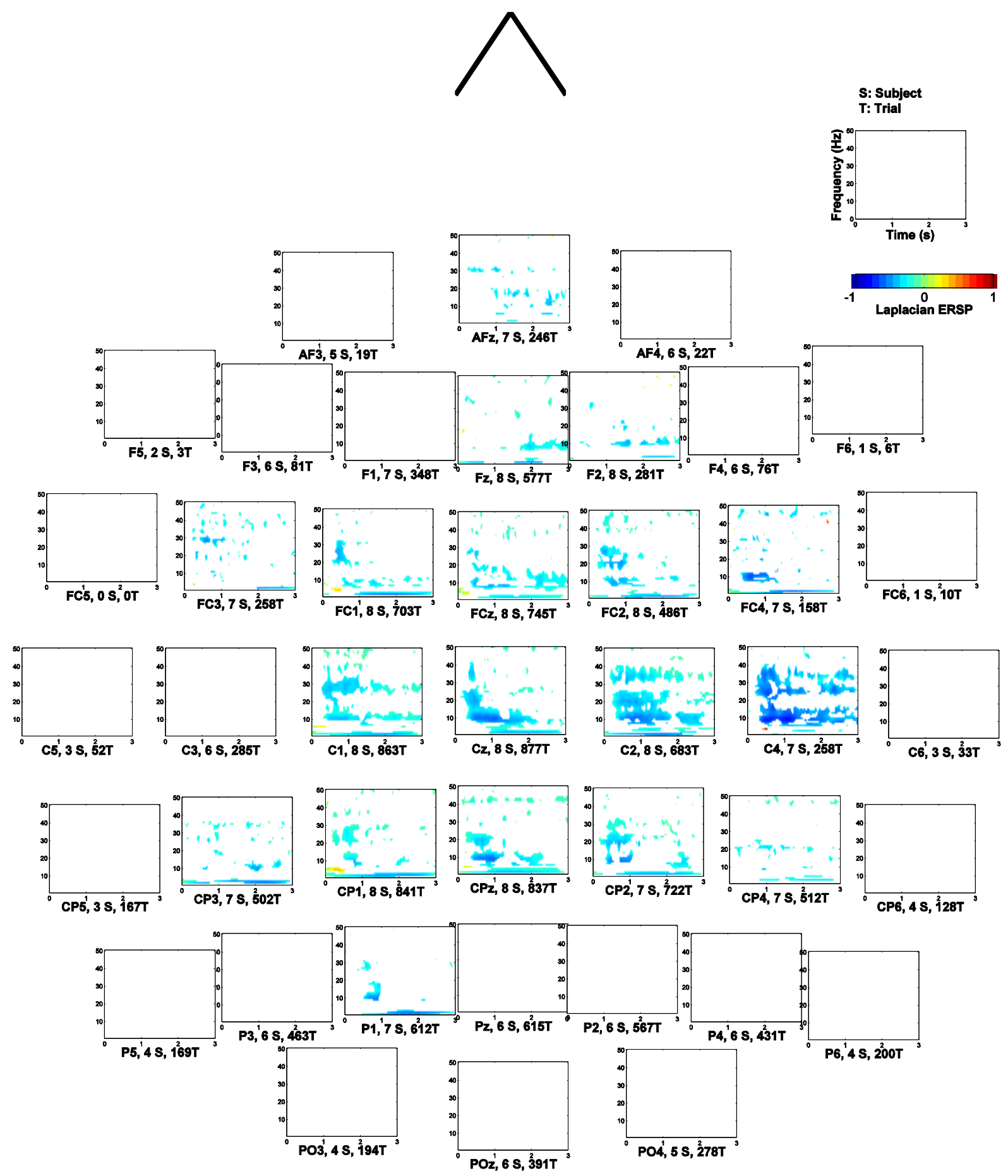

Figure S10. Event-Related Spectral Perturbation (ERSP) of surface Laplacian EEG (ERD/ERS ratio) across scalp electrodes, averaged across 8 subjects during execution (GO) stage. For each electrode position the significant normalized continuous wavelet scalograms are plotted at $\alpha=0.05$ after correction for multiple comparisons. 

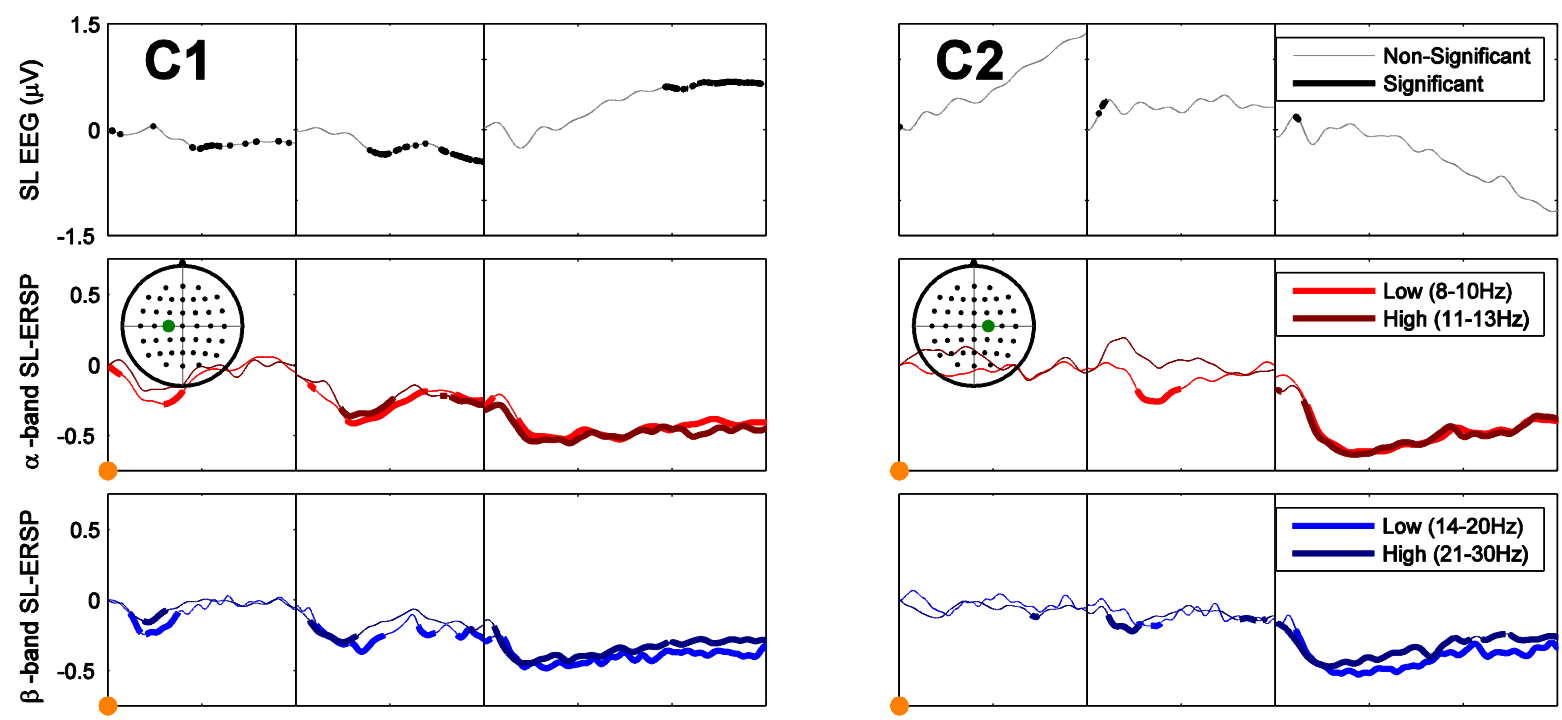

All ERSP Referenced and Normalised to Baseline Power at AC Onset
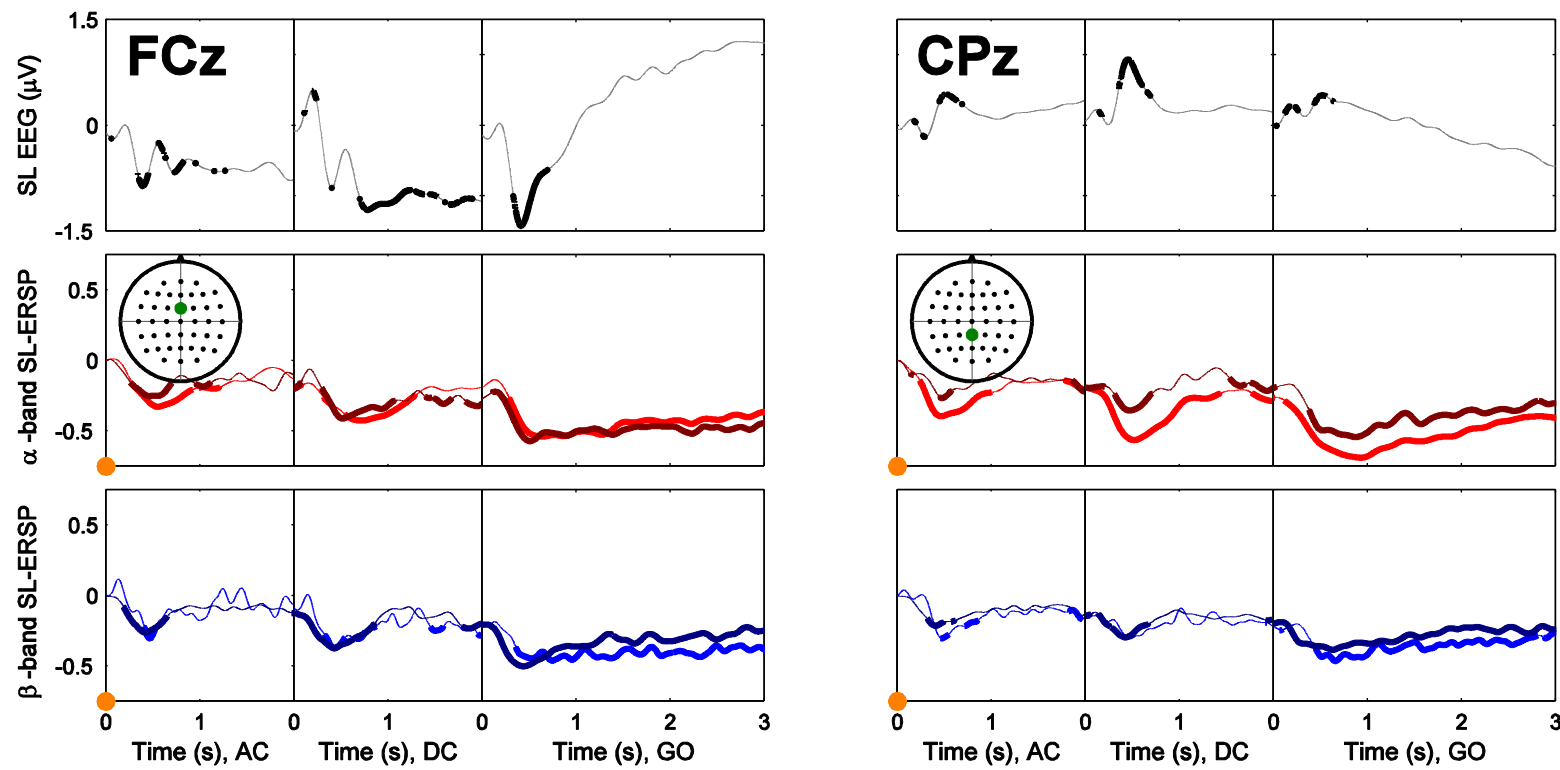

Figure S11. Accumulated ERD/ERS patterns corresponding to the results in Figure 7. All ERSP in all stages are referenced and normalised to the baseline power at AC onset time, as opposed to referencing and normalising to the baseline power at the onset of the most recent cue in each stage. Surface Laplacian ERP (black), $\alpha$-band ERD/ERS (red) and $\beta$-band ERD/ERS (blue) at 4 selected electrodes $\mathrm{C}_{1}, \mathrm{C}_{2}, \mathrm{FC}_{\mathrm{z}}$ and $\mathrm{CP}_{\mathrm{z}}$ averaged across 8 subjects during preparation (AC), planning (DC) and execution (GO) stages. Significant at $\alpha=0.05$ after correction for multiple comparisons. 
Table S1. Significant ear-lobe-referenced ERD/ERS across all subjects for all electrodes.

\begin{tabular}{|c|c|c|c|c|c|c|}
\hline$\overline{\mathrm{Ch}}$ & AC (Transient) & AC (Sustained) & DC (Transient) & DC (Sustained) & GO (Transient) & GO (Sustained) \\
\hline $\mathrm{Cz}$ & $-[18-20]$ & & $\begin{array}{l}-[7-8] \\
-[18-20]\end{array}$ & $-[8]$ & $\begin{array}{l}-[8-9] \\
-[19]\end{array}$ & $-[3]$ \\
\hline $\mathrm{C} 1$ & $\begin{array}{l}-[16-20] \\
-[24-26]\end{array}$ & & $\begin{array}{l}-[7-9] \\
-[17-21]\end{array}$ & $\begin{array}{l}+[1] \\
-[8]\end{array}$ & $\begin{array}{l}-[6] \\
-[8-9] \\
-[19-20]\end{array}$ & $-[3]$ \\
\hline $\mathrm{C} 2$ & $-[19-20]$ & & $-[7-8]$ & $-[2]$ & $\begin{array}{l}-[6] \\
-[8-9] \\
-[18-20]\end{array}$ & $\begin{array}{l}-[3] \\
-[9]\end{array}$ \\
\hline $\mathrm{C} 3$ & $\begin{array}{l}-[16-20] \\
-[24]\end{array}$ & & $\begin{array}{l}-[7-9] \\
-[15-21]\end{array}$ & $+[1]$ & $\begin{array}{l}-[6] \\
-[8-10] \\
-[12] \\
-[18-20]\end{array}$ & $-[3]$ \\
\hline $\mathrm{C} 4$ & $\begin{array}{l}-[8-9] \\
-[17-18]\end{array}$ & $-[3]$ & $+[4]$ & $-[2]$ & $\begin{array}{l}-[6] \\
-[8-9] \\
-[18-21]\end{array}$ & $\begin{array}{l}-[3] \\
-[7-8]\end{array}$ \\
\hline C6 & $\begin{array}{l}-[9] \\
-[17-18]\end{array}$ & & $-[7-8]$ & $-[2-3]$ & & \\
\hline $\mathrm{FCz}$ & $\begin{array}{l}-[17-22] \\
-[46-47]\end{array}$ & & $\begin{array}{l}-[8-9] \\
-[19-21] \\
-[27-28] \\
-[38]\end{array}$ & $-[7-8]$ & & $-[3]$ \\
\hline $\mathrm{FC} 1$ & $-[17-27]$ & & $\begin{array}{l}-[8-9] \\
-[19] \\
-[21] \\
-[27-28] \\
-[38]\end{array}$ & & & $-[3]$ \\
\hline $\mathrm{FC} 2$ & $\begin{array}{l}-[17-19] \\
-[46-47]\end{array}$ & & $\begin{array}{l}-[7-8] \\
-[38]\end{array}$ & $-[7-8]$ & $-[9]$ & $\begin{array}{l}-[3] \\
-[9-10]\end{array}$ \\
\hline $\mathrm{FC} 3$ & $-[24]$ & $-[3]$ & $\begin{array}{l}-[8] \\
-[27-29]\end{array}$ & $+[1]$ & & \\
\hline $\mathrm{FC} 4$ & $-[17-18]$ & $-[3]$ & $-[7-8]$ & & $-[8-9]$ & $\begin{array}{l}-[3] \\
-[8]\end{array}$ \\
\hline FC5 & $\begin{array}{l}-[3] \\
-[8] \\
-[17] \\
-[44]\end{array}$ & & & & & $-[8]$ \\
\hline FC6 & $-[3]$ & & & $-[2]$ & $\begin{array}{l}+[6] \\
-[28]\end{array}$ & \\
\hline $\mathrm{CPz}$ & $-[8-9]$ & & $\begin{array}{l}-[7-9] \\
-[18-19]\end{array}$ & $+[1]$ & $\begin{array}{l}-[6] \\
-[8-9]\end{array}$ & $-[3-6]$ \\
\hline $\mathrm{CP} 1$ & $\begin{array}{l}-[9-10] \\
-[16-17]\end{array}$ & & $\begin{array}{l}-[7-9] \\
-[17-20]\end{array}$ & $+[1]$ & $\begin{array}{l}-[6] \\
-[8-9]\end{array}$ & $-[3-6]$ \\
\hline $\mathrm{CP} 2$ & $\begin{array}{l}-[8-9] \\
-[19-20]\end{array}$ & & $\begin{array}{l}-[7-9] \\
-[17-19]\end{array}$ & & $\begin{array}{l}-[6] \\
-[8-9] \\
-[17]\end{array}$ & $-[3-6]$ \\
\hline $\mathrm{CP} 3$ & $\begin{array}{l}-[9-10] \\
-[16-20]\end{array}$ & & $-[16-20]$ & $+[1]$ & $\begin{array}{l}-[6] \\
-[8-12]\end{array}$ & $-[3-4]$ \\
\hline $\mathrm{CP} 4$ & $\begin{array}{l}-[17-19] \\
-[24-25]\end{array}$ & & $\begin{array}{l}-[7-9] \\
-[17-19]\end{array}$ & & $\begin{array}{l}-[6-9] \\
-[15-17]\end{array}$ & $-[3-5]$ \\
\hline
\end{tabular}




\begin{tabular}{|c|c|c|c|c|c|c|}
\hline CP5 & $-[12-15]$ & & $\begin{array}{l}-[8] \\
+[41-43]\end{array}$ & & $-[10-12]$ & $-[12]$ \\
\hline CP6 & $\begin{array}{l}-[8-9] \\
-[16-19] \\
-[23-24] \\
-[30-31]\end{array}$ & & $\begin{array}{l}-[7-11] \\
-[16-19]\end{array}$ & $-[18]$ & $-[7]$ & $-[3]$ \\
\hline $\mathrm{Fz}$ & $-[19]$ & $-[3]$ & $\begin{array}{l}-[7-8] \\
-[26-29]\end{array}$ & & & $-[11-15]$ \\
\hline F1 & & $-[3]$ & $\begin{array}{l}-[7] \\
-[27-28] \\
-[36-39]\end{array}$ & & & $-[11-16]$ \\
\hline $\mathrm{F} 2$ & & $-[3]$ & $\begin{array}{l}-[7-8] \\
-[28] \\
-[38-39]\end{array}$ & $-[2]$ & & $-[11-12]$ \\
\hline F3 & $\begin{array}{l}-[4-5] \\
-[18] \\
-[20]\end{array}$ & $-[3]$ & & & & \\
\hline $\mathrm{F} 4$ & & & $-[7-8]$ & & & \\
\hline $\mathrm{Pz}$ & $-[8]$ & & $-[8]$ & $+[1]$ & $\begin{array}{l}-[6-8] \\
-[10-13] \\
-[17-18]\end{array}$ & $\begin{array}{l}-[3-7] \\
-[9]\end{array}$ \\
\hline P1 & $\begin{array}{l}-[8-9] \\
-[20]\end{array}$ & & $\begin{array}{l}-[7-8] \\
-[18-20]\end{array}$ & $+[1]$ & $\begin{array}{l}-[6-8] \\
-[11-12]\end{array}$ & $\begin{array}{l}-[3-5] \\
-[7]\end{array}$ \\
\hline $\mathrm{P} 2$ & $-[9]$ & & $\begin{array}{l}+[4] \\
-[7-8] \\
-[10-11]\end{array}$ & & $\begin{array}{l}-[8] \\
-[10-18]\end{array}$ & $\begin{array}{l}-[3-4] \\
-[9]\end{array}$ \\
\hline $\mathrm{P} 3$ & $-[8]$ & & $\begin{array}{l}-[19-20] \\
+[41-42]\end{array}$ & $+[1]$ & $\begin{array}{l}-[7] \\
-[11-13]\end{array}$ & $-[3-7]$ \\
\hline $\mathrm{P} 4$ & $-[8]$ & & $-[7-11]$ & $-[2]$ & $-[10-14]$ & $-[4-5]$ \\
\hline P5 & $\begin{array}{l}-[12] \\
-[46]\end{array}$ & & & & & \\
\hline P6 & $-[7-8]$ & & $-[7-11]$ & $-[2]$ & $-[9-13]$ & $-[3-4]$ \\
\hline $\mathrm{AFz}$ & & $-[3]$ & & & & $-[11-16]$ \\
\hline AF3 & & & & & $+[5]$ & \\
\hline $\mathrm{AF} 4$ & & & & & $+[5]$ & $-[10-12]$ \\
\hline $\mathrm{PO} 3$ & $-[19]$ & & & $-[3-4]$ & & $-[3-4]$ \\
\hline
\end{tabular}


Table S2. Significant surface Laplacian ERD/ERS across all subjects for all electrodes.

\begin{tabular}{|c|c|c|c|c|c|c|}
\hline Ch & AC (Transient) & AC (Sustained) & DC (Transient) & DC (Sustained) & GO (Transient) & GO (Sustained) \\
\hline $\mathrm{Cz}$ & $\begin{array}{l}-[2] \\
-[22]\end{array}$ & $-[2]$ & $\begin{array}{l}+[4-6] \\
-[7] \\
-[19-22]\end{array}$ & $\begin{array}{l}-[2] \\
-[22]\end{array}$ & $-[8-25]$ & $-[2-3]$ \\
\hline $\mathrm{C} 1$ & $\begin{array}{l}-[2] \\
-[9] \\
-[15-17]\end{array}$ & $-[2-3]$ & $\begin{array}{l}-[2] \\
+[5-6] \\
-[7-10] \\
-[14-25]\end{array}$ & $\begin{array}{l}-[2-3] \\
-[7-8]\end{array}$ & $\begin{array}{l}-[1-2] \\
+[6] \\
-[10-17] \\
-[22] \\
-[24-32] \\
-[38-39] \\
-[47-48]\end{array}$ & $\begin{array}{l}-[1-3] \\
-[10-12] \\
-[27-28]\end{array}$ \\
\hline $\mathrm{C} 2$ & $-[2]$ & & $\begin{array}{l}-[2] \\
-[7] \\
+[12]\end{array}$ & $-[2-3]$ & $\begin{array}{l}-[2] \\
-[8] \\
-[10-25] \\
-[32-40]\end{array}$ & $\begin{array}{l}-[5] \\
-[8-13] \\
-[20]\end{array}$ \\
\hline $\mathrm{C} 4$ & $\begin{array}{l}-[2-4] \\
-[6]\end{array}$ & & $\begin{array}{l}-[8] \\
-[28-29]\end{array}$ & $-[2]$ & $\begin{array}{l}-[8-16] \\
-[21-38]\end{array}$ & $\begin{array}{l}-[8-11] \\
-[13-15] \\
-[25-28] \\
-[33-34]\end{array}$ \\
\hline $\mathrm{FCz}$ & $\begin{array}{l}+[4] \\
+[6] \\
-[7-13] \\
-[22-29] \\
-[41]\end{array}$ & & $\begin{array}{l}+[3-5] \\
+[7] \\
-[8-9] \\
-[17] \\
-[21-23]\end{array}$ & $-[2]$ & $\begin{array}{l}-[2] \\
+[5] \\
-[7-9] \\
-[17-19] \\
-[28]\end{array}$ & $\begin{array}{l}-[2-3] \\
-[8] \\
-[11-14]\end{array}$ \\
\hline $\mathrm{FC} 1$ & $\begin{array}{l}-[1-2] \\
+[5] \\
-[7] \\
-[20-29]\end{array}$ & $-[1-2]$ & $\begin{array}{l}+[6] \\
-[22-29]\end{array}$ & $-[2]$ & $\begin{array}{l}-[2] \\
+[5] \\
-[7-9] \\
-[19-22] \\
-[30-31]\end{array}$ & $-[2-3]$ \\
\hline $\mathrm{FC} 2$ & & $-[2]$ & & & $\begin{array}{l}-[2] \\
-[9-12] \\
-[18-22] \\
-[25-29] \\
-[47]\end{array}$ & $-[2]$ \\
\hline FC3 & & & $\begin{array}{l}-[2] \\
-[11-12] \\
-[19-20] \\
-[22-23] \\
-[29-32]\end{array}$ & & $-[28-30]$ & $-[2]$ \\
\hline FC4 & & & $-[8]$ & $-[3]$ & $\begin{array}{l}-[1-2] \\
-[8-12] \\
-[31]\end{array}$ & $-[2]$ \\
\hline $\mathrm{CPz}$ & $\begin{array}{l}-[2-10] \\
-[17-23] \\
-[46]\end{array}$ & $\begin{array}{l}-[2-6] \\
-[8]\end{array}$ & $\begin{array}{l}-[2-3] \\
+[4] \\
-[6-10]\end{array}$ & $-[2-3]$ & $\begin{array}{l}-[2] \\
+[5] \\
-[6] \\
-[9-13] \\
-[17-23] \\
-[41-43]\end{array}$ & $\begin{array}{l}-[2-4] \\
-[6]\end{array}$ \\
\hline $\mathrm{CP} 1$ & $\begin{array}{l}-[2-3] \\
-[5-11] \\
-[16-26]\end{array}$ & $-[2-4]$ & $\begin{array}{l}-[2-3] \\
-[6-10] \\
-[16-21] \\
-[23] \\
-[30-31]\end{array}$ & $\begin{array}{l}-[2] \\
-[6-8] \\
-[16]\end{array}$ & $\begin{array}{l}-[1-3] \\
+[5-6] \\
-[11-14] \\
-[21-29] \\
-[37]\end{array}$ & $-[2-3]$ \\
\hline $\mathrm{CP} 2$ & $\begin{array}{l}-[2-3] \\
-[6] \\
-[9]\end{array}$ & $-[2-3]$ & $\begin{array}{l}-[2] \\
-[18-21] \\
-[28-29]\end{array}$ & $-[2]$ & $\begin{array}{l}-[2] \\
-[9-11] \\
-[19-25]\end{array}$ & $\begin{array}{l}-[2-3] \\
-[6] \\
-[8]\end{array}$ \\
\hline
\end{tabular}




\begin{tabular}{|c|c|c|c|c|c|c|}
\hline & $\begin{array}{l}-[18-20] \\
-[23-25]\end{array}$ & & & & $-[28-32]$ & \\
\hline $\mathrm{CP} 3$ & & & $-[22]$ & $-[2]$ & $\begin{array}{l}-[2-3] \\
-[27]\end{array}$ & $-[2-3]$ \\
\hline $\mathrm{CP} 4$ & $\begin{array}{l}-[2] \\
-[44]\end{array}$ & & & & $-[21-22]$ & $-[3]$ \\
\hline $\mathrm{Fz}$ & $-[2]$ & & & & $-[2]$ & $-[10-13]$ \\
\hline $\mathrm{F} 2$ & $-[2]$ & $-[3]$ & & & & $\begin{array}{l}-[3] \\
-[10-12]\end{array}$ \\
\hline P1 & $\begin{array}{l}-[2] \\
-[23]\end{array}$ & $-[2]$ & $-[9]$ & $-[4]$ & $\begin{array}{l}-[1] \\
-[10-13] \\
-[18] \\
-[27]\end{array}$ & $-[1-2]$ \\
\hline $\mathrm{AFz}$ & & & & & $-[30-31]$ & \\
\hline
\end{tabular}

+ shows ERS and - shows ERD. Numbers show frequency range in Hz. Transient means the first 1.0s after the cue where early activity is observed. Sustained, indicates the lasting activity that is sustained in the second second (for AC and DC) or third second (for GO) after the cue. 